\title{
تداعيات جائحة كورونا على تحويلات العاملين المصريين بالخارج
}

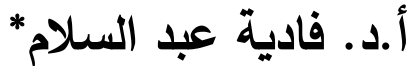

\section{مقدمة}

يعد فيروس كورونا من أخطر الصدمات التي يتعرض لها الاقتصاد العالمي في الوقت الراهن،

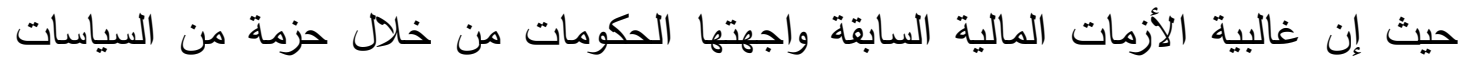

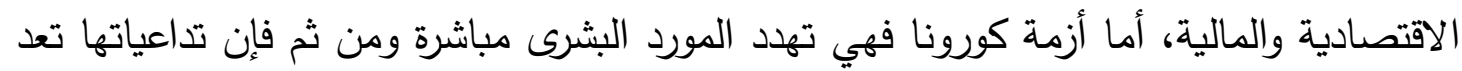
الأخطر على الاقتصاد العالمي وتتطلب سياسات مختلفة لمواجهتها.

ويختلف الأمر في مصر، فهي آمنة من وقع الأزمة المباشر في ضوء الإجراءات الاحترازية التي

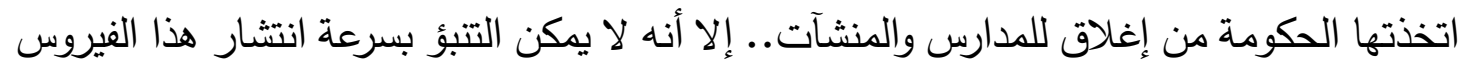

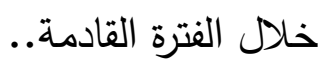

وتعد تحويلات العاملين المصريين في الخارج أحد مصادر النقد الأجنبي التي يعتمد عليها في

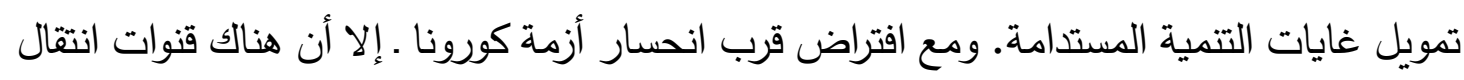
لأثر هذه الأزمة على الاقتصاد المصري من خلال تداعيات الأزمة على مصادر النقد الأجنبي ومن بينها تحويلات العاملين الهصريين في الخارج بالتركيز على مفهوم الهجرة المؤقتة وحاملي التيل

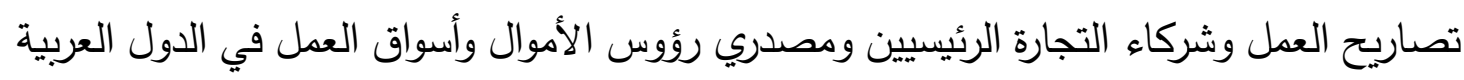

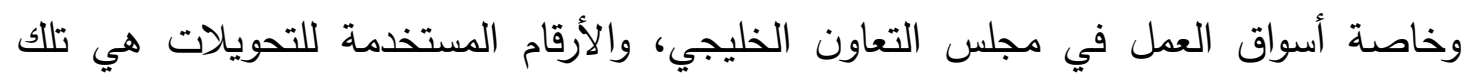

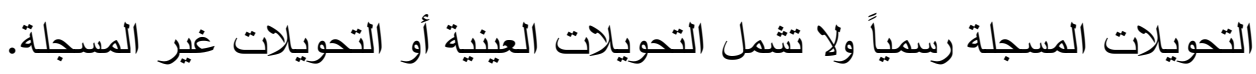

وبالرغم من أن التحويلات العينية يمكن تقديرها خلال استخدام المسوحات المكثة للمهاجرين إلا

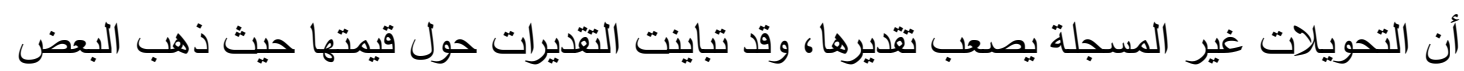

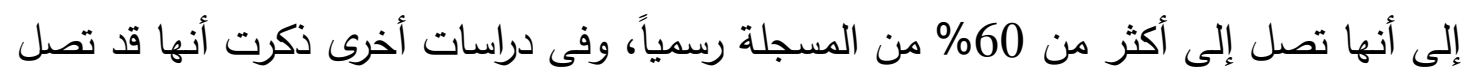
إلى مرتين أو ثلاث مرات تلك المسجلة رسمياً.

لذلك تهتم الورقة بعدة أمور منها: إلقاء الضوء حول تداعيات كورونا على مسار الهجرة والتحويلات،

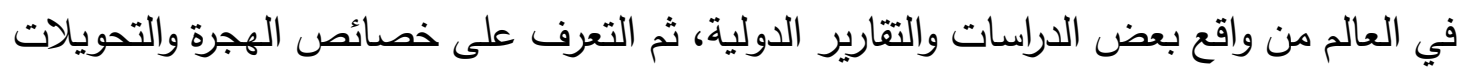
حيث كثف انتشار فيروس كورونا المستجد عن هشاشة أسواق العمل وصعوبة استدامة التحويلات 
حيث إنه بالرغم من اتفاق الدول النامية والمتقدمة على العديد من التدابير الاحتوائية للأزمة إلا أن

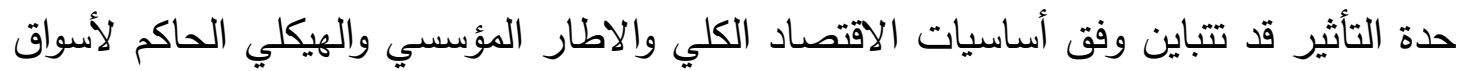
العمل والتحويلات وسوق النفط العالمي، ولدراسة تداعيات أزمة كورونا على تحويلات العاملين

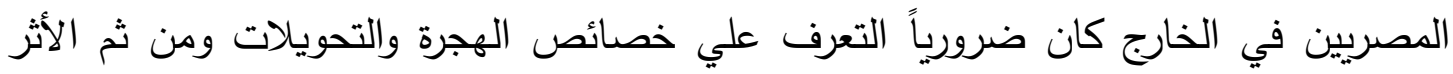

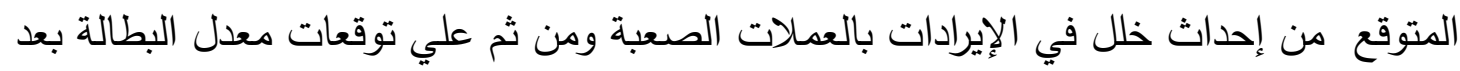
عودة جزء من العمالة ونطاق الاستغناءات المحتملة.

\section{1-نظرة عامة حول تداعيات كورونا على مسارات الهجرة والتحويلات في العالم}

من المتوقع أن تتخفض التحويلات العالمية على نحو حاد بحوالي 20\% في 2020 لسبب الأزمة

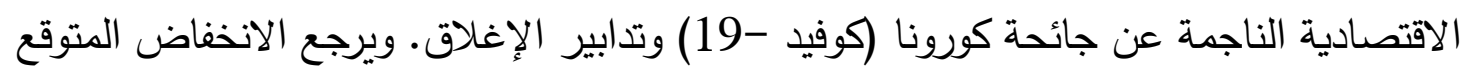

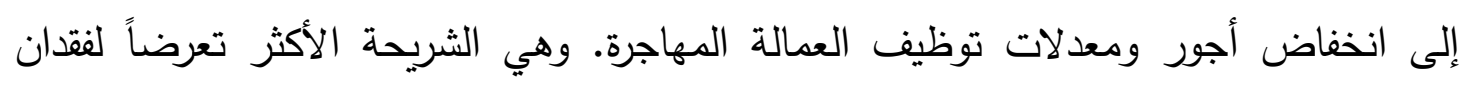

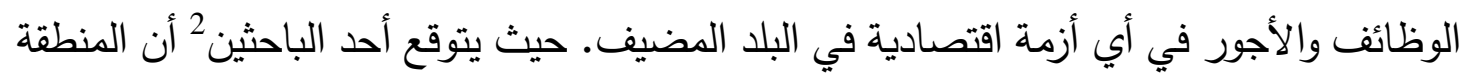

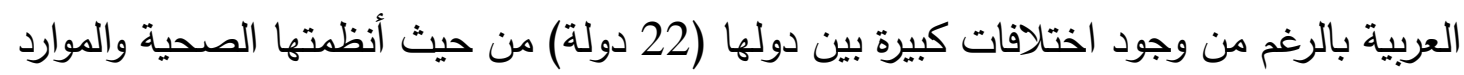

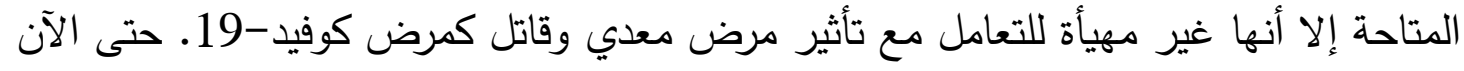

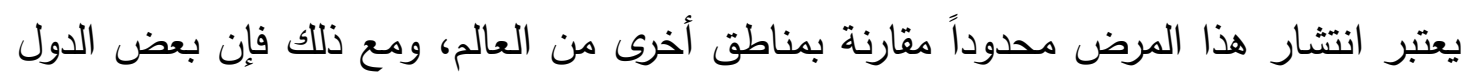
الأكثر تأثراً بفيروس كورونا المستجد تتواجد في الجوار المباشر لدول مثل إيطاليا وإسبانيا وإيران، بالإضافة إلى ذلك تتمتع المنطقة بعلاقات تجارية وجيوسياسية وثيقة مع دول في أوروبا وأمريكا

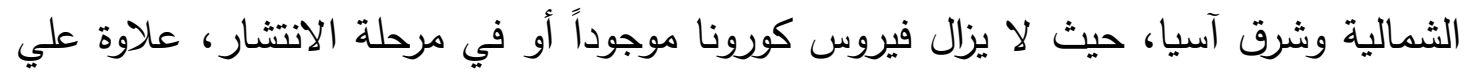

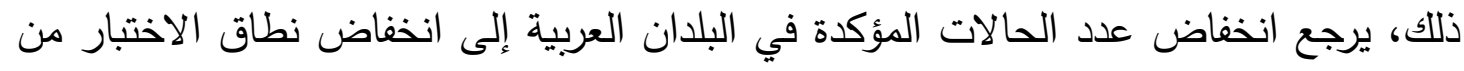

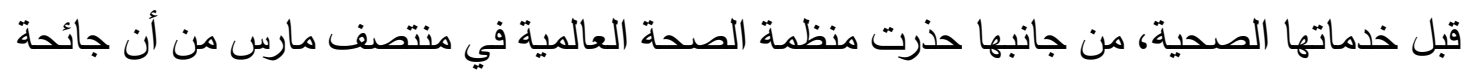
كوفيد لم تصل بعد إلي ذروتها في الشرق الأوسط وشمال أفريقيا.

فيما يخص الدول الست الأعضاء في مجلس التعاون الخليجي (الإمارات، البحرين، السعودية،

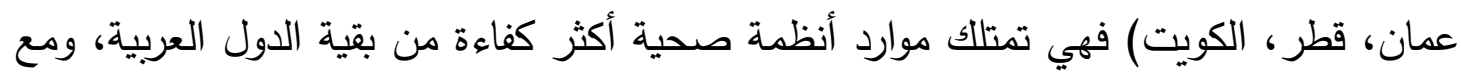

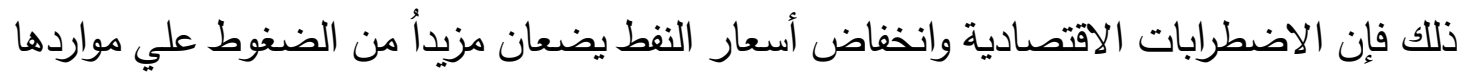

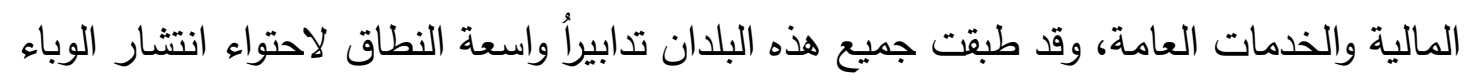


ومع ذلك، هنالك خطر كبير من الإصابة بالعدوى بين العمال الأجانب ( في بعض دول الخليج

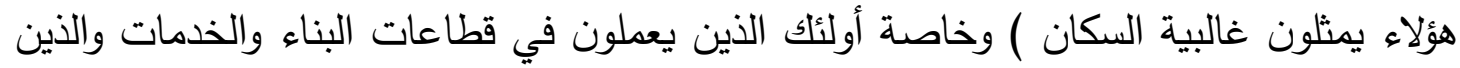
يعيشون في ظروف مزدحمة لا يتوافر فيها الخدمات الصحية المناسبة.

من جهة أخرى يمكن أن يكون لهذا الوضع الجديد تأثيراً كبيراً على قطاعات السياحة والنقل الدولي في دول الخليج وكنلك على قطاعات العقارات والفاعليات العالمية الكبرى التي ستقام في تلكك المنطقة مثل اكسبو 2020 في دبي واجتماع مجموعة العشرين يجعل من الصعب أداء هذه الوظيفة بنجاح في وقت حرج بالنسبة للنظام العالمي.

ستكون النتيجة النهائية لهذه الأزمة بالنسبة للدول العربية مشروطة بعدة عوامل: مثل مدة حالة الطوارئ الصحية الدولية، وفعالية السياسات الحكومية في التخفيف من آثارها الصحية والاجتماعية

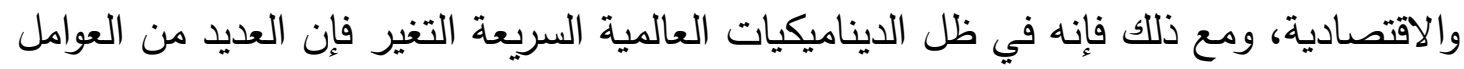

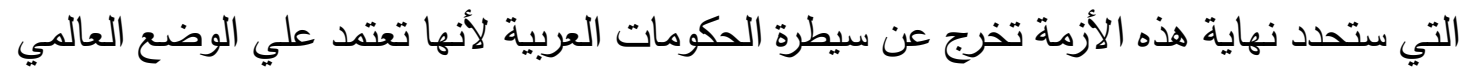

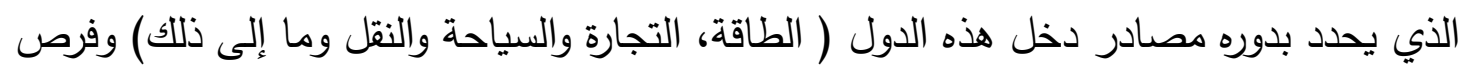

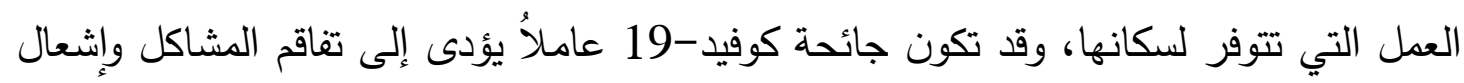

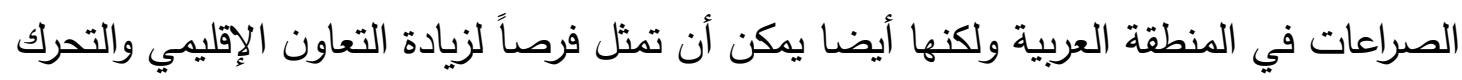
نحو الحكم الرشيد وتغير مسار النزاعات المسلحة.

بالرغم من أنه يتم منح إعفاءات للمهن الرئيسية مثل العلماء والأطباء والصحفيين القادة الحكوميين

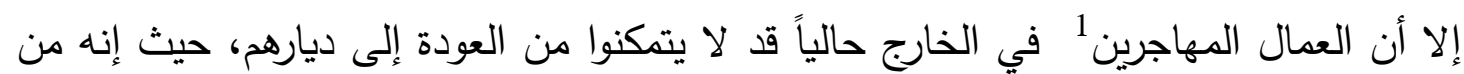
المتصور استجابة للحجر الصحي الحالي والمستقبلي ستقوم الشركات بتطوير قدرات الأتمتة

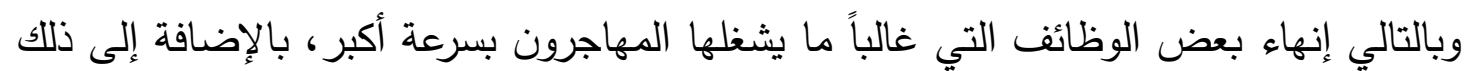
ففي معظم الصناعات ستتركز عمليات تسريح بعض الموظفين نتيجة انتشار الفيروس علي العمال

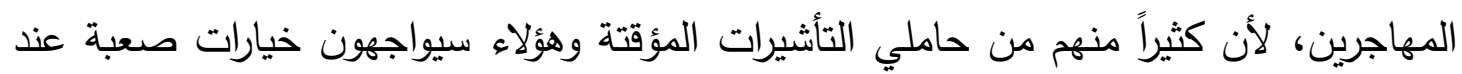
الاستغناء عنهم، فإما العثور علي وظيفة أخرى أو الحصول علي حني نوع مختلف من التأثيرات،

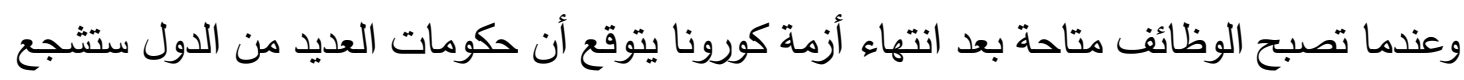

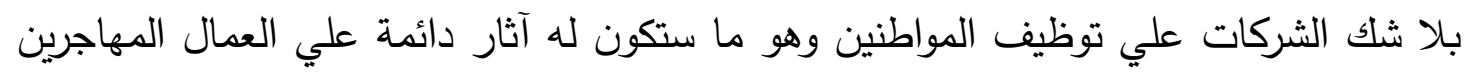
1 ايرول بيبوك -اتساع الفجوات: اتجاهات تأثير وباء كورونا على الهجرة العالمية - مركز المستقبل للأبحاث والدارسات المتقدمة، الثثلاثاء، 7 ابريل 2020 عرض باسم راشد. Errol yay-boke، five ways Coved 019 TsChangeing Global Migration, Centre for Strategic andInternational Studies. 
وأسرهم ومجتمعاتهم وبالتالي تتسع الفجوة بين الدول الأكثر ثراءً والأكثر فقراً، ويشار أيضاً إلى أن العديد من العمال المهاجرين وخاصة من ذوى المهارات المتدنية ليس لديهم خيار العمل من المنزل

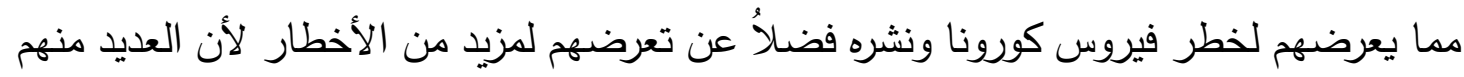
لا يحصلون علي رعاية صحية مناسبة، ومع القيود المفروضة علي المدى القصير فإن النازحين قسراً والمهاجرين سيكونون في خطر متزايد حيث يقيم 84\% من اللاجئين، 99\% معائة من النازحين داخلياً في المناطق التي وصلها الفيروس حديثاً.

وبالإضافة إلى ما تقدم هناك أدلة متزايدة على أن القيود المفروضة على الهجرة الآمنة والمنظمة

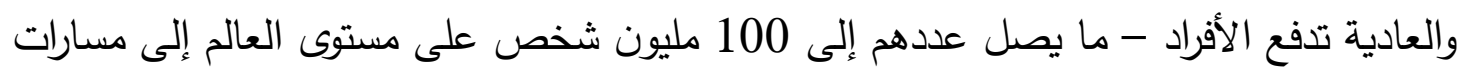
غامضة للهروب من الأذى عبر الهجرة غير الشرعية.

من المتوقع أن تتخفض التحويلات إلى البلدان المنخفضة والمتوسطة الدخل بنسبة 19,7\% لتصل

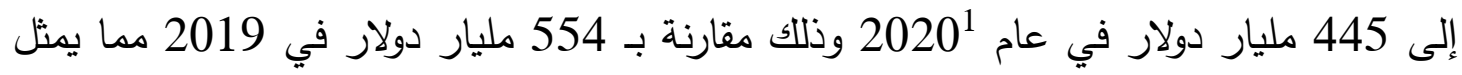

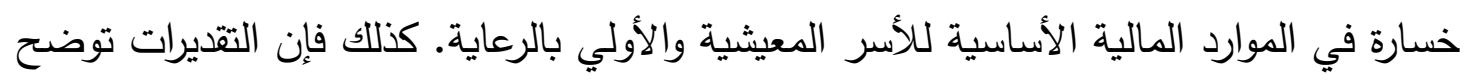

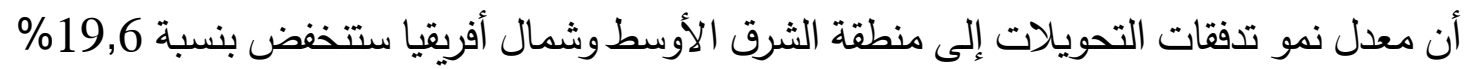
في عام 2020 ثم تتحسن بنسبة 1,6\% في عام 2021، ويوضح البنك الدولي أن عام 2019 قد شهر تطور تدفقات التحويلات إلى الدول المنخفضة ومتوسطة الدخل بما يفوق الاستثمار الأجنبي المباشر بحيث أصبحت هذه التدفقات مصدراً رئيسياً لهذه الدول.

وتوضح الدراسات السابق الإشارة إليها أن التحويلات تعمل على التخفيف من وطأة الفقر في

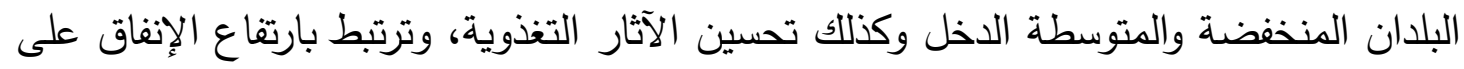
التعليم وتحد من عمالة الأطفال، ويؤثر انخفاض التحويلات على قدرة الأسر على الإنفاق على الإنى الإنى

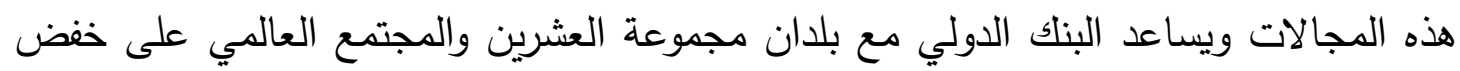
تكاليف التحويلات وتحسين الثمول المالي للفقراء.

World Bank Group, COVID-19 Crisis through a Migration lens, Migration and Development ${ }^{1}$

Brief 32, April 2020, p. 8, table (1-2) وذكر التقرير بأن هذا الانخفاض لا يرجع إلى الانخفاض في أعاد المهاجرين الدوليين ولكن لدا كبير نتيجة الانخفاض في الأجور

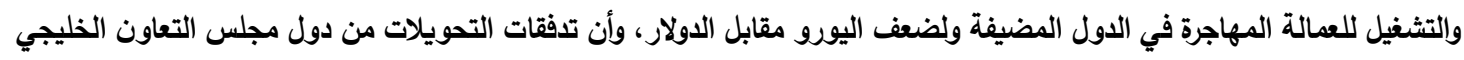
ستتأثر بالركود تحت تأثير تداعيات كورونا وكنلك بالهبوط في أسعار النفط. 
ومن المتوقع أن تتخف تدفقات التحويلات في أوروبا وآسيا الوسطى بنسبة (27,5\%) في عام 2020 تليها أفريقيا جنوب الصحراء (23,1\%) وجنوب آسيا (22,1\%) والشرق الأوسط وشمال

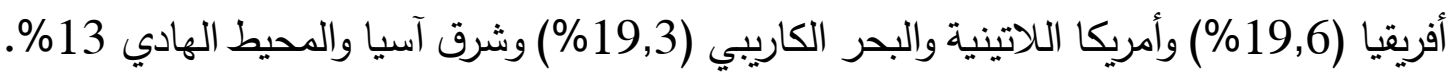

ومن المتوقع أيضا أن تصبح تدفقات التحويلات أكثر أهية لهذه المجموعة من البلدان المنخفضة

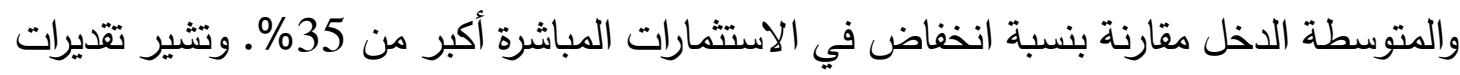

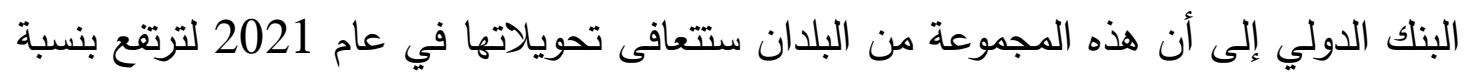
5,6 لتصل إلى 470 مليار دولار في 2021، وهذه الآفاق من تدفقات التحويلات تكتفها

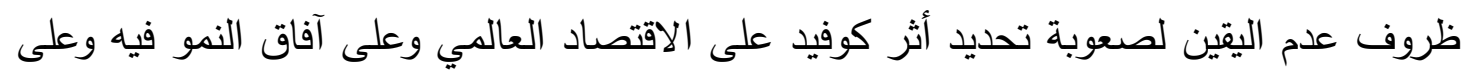
تدابير الحد من انتشار هذا المرض، وفي الماضي كانت التحويلات تقوم بدور في مواجهة التقلبات

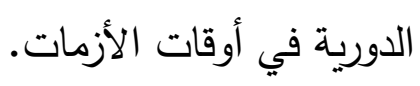

ومن المتوقع أن تنخف التحويلات إلى منطقة الشرق الأوسط وشمال أفريقيا بنسبة 19,6\%

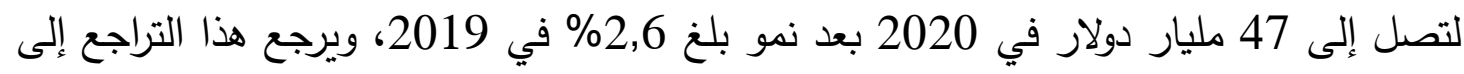
تباطؤ النمو العالمي وأثر انخفاض أسعار النفط في بلدان مجلس التعاون الخليجي، وكذللك يتوقع

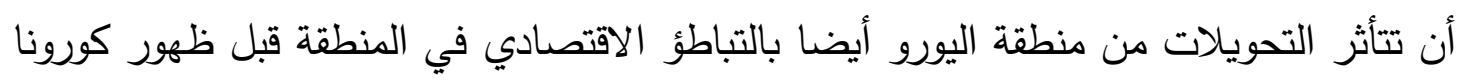

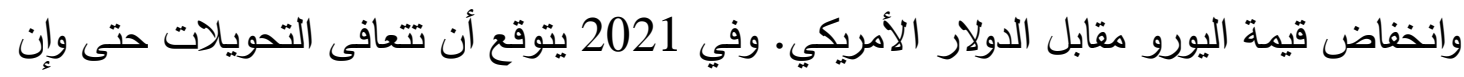

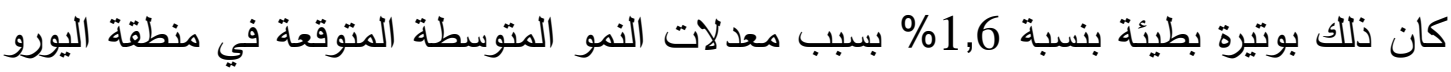
وضعف التدفقات إلى الخارج من بلدان مجلس التعاون الخليجي.

\section{تكلفة إرسال التحويلات}

أما ما يخص تكاليف التحويلات لمبلغ 200 دولار إلى المنطقة فتسجل 7\% ولم تتغير هذه النسبة كثيراً عما سبق وتتراوح تكلفة إرسال الأموال من بلدان مجلس التعاون الخليجي إلى مصر والأردن

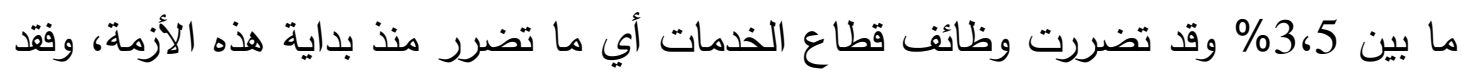

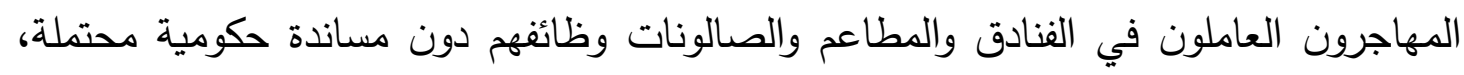
والأسوأ من ذلك أنهم لا يستطيعون حتى العودة إلى بلدانهم لسبب قيود السفر، وتحتاج هذه

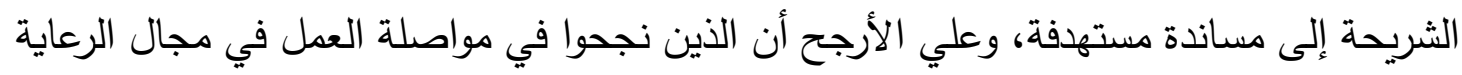

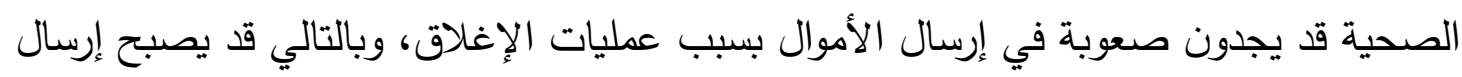

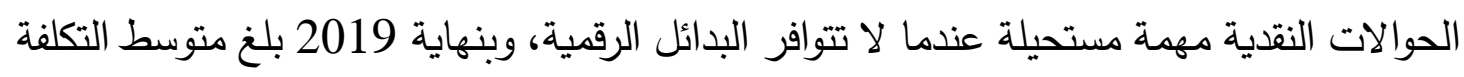
العالمية لتحويل 200 دولار 6,82\% أو 13,84 دولار ويرمي الهدف رقم 10 من أهداف التتمية 
المستدامة إلى تقليل هذه التكلفة إلى 6 دولارات في المتوسط في 2030 ولذلك يوصي البنك الدولي ببعض الإجراءات دعماً لقطاع التحويلات 1 :

ينبغي للسلطات العامة والحكومية معاملة شركات ومكاتب تقديم خدمات التحويلات بوصفها خدمات أساسية وضرورية أن تخفف من أي أثر على تشغيل هذه الثركات والمكاتب. يتعين مساندة صناعة التحويلات المالية بالأدوات المناسبة لإدارة مخاطر الائتمان والسيولة لدانة على نحو فعال. خفض أسعار التحويلات لمواجهة تحديات انتشار البطالة والمحنة التي تواجه الجاليات المهاجرة في البلدان المضيفة. اعتماد نماذج التحويلات خلال الوسائل الرقمية.

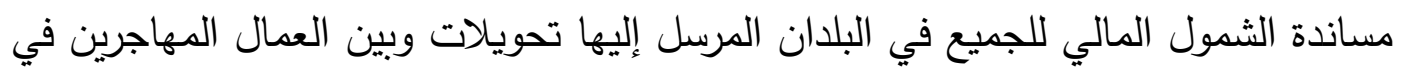

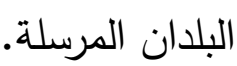

ولذلك هنالك دعوة للتحرك علي المدى المتوسط، حيث سيعتمد انتعاش تدفقات التحويلات اعتماداً كبيراً علي نجاح جهود التحفيز الاقتصادي لمجموعة العشرين وغيرها من الدول المرسلة لصافي الصئي

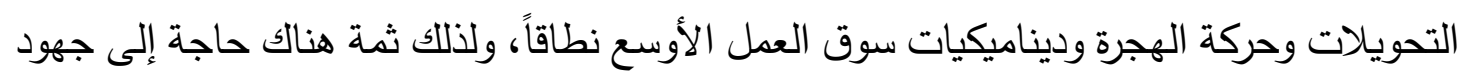

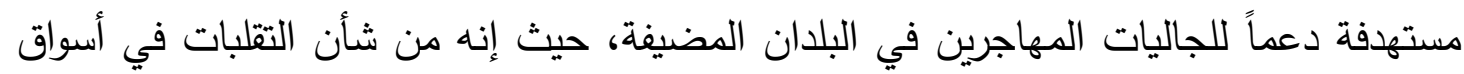

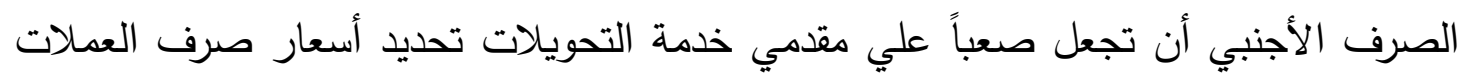

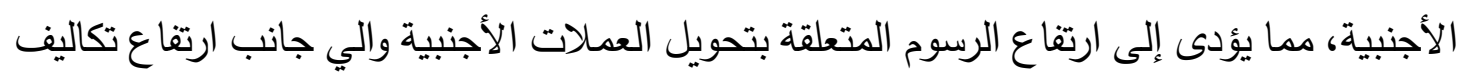

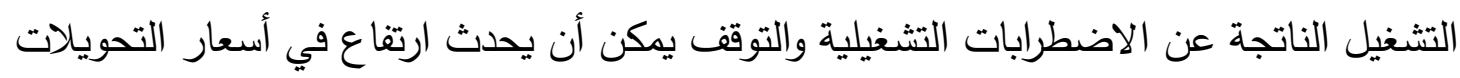
علي المدى القصير كذلك فإن أنظمة الحماية الاجتماعية الفعالة من الأهمية بمكان لحماية الفئات

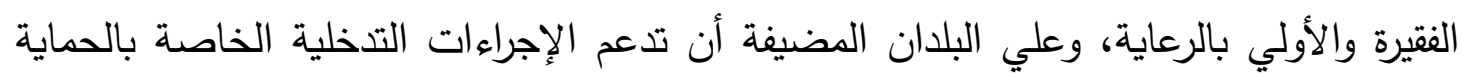

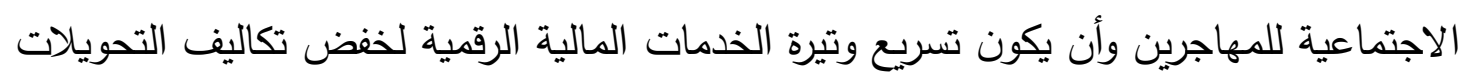
أولوية قصوى بمجرد استقرار الأزمة العالمية، حيث لا تزال متوسط التكلفة العالمية لتحويل 200 دولار هي 6.8\% في الربع الأول من عام 2020.

1 الفولثوجارسيا مورا، ميكال رونكوفسكي، التحويلات في زمن فيروس كورونا، الحفاظ على تدفقها. https: II blogs .world ban K . Org larl voices Iremittances - times - Coronavirus - keep - them 
تعزيز الامتثال لإجراءات وضوابط مكافحة غسل الأموال ومحاربة تمويل الإرهاب وتطوير الحلول الرقمية للتعرف على الهوية.

على الرغم من الهبوط المتوقع في تدفقات التحويلات إلا أن مجموعة البنك الدولي ${ }^{1}$ تتوقع أن

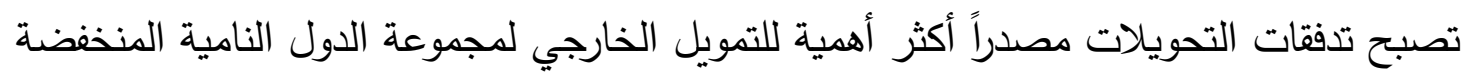

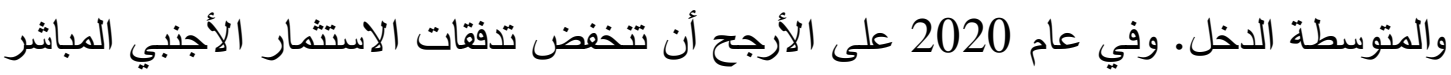

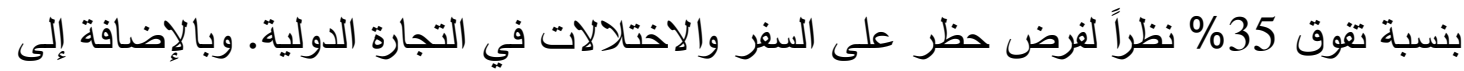
الانخفاضات في أسعار الأسهم للشركات دولية النشاط فإن تدفقات الدحافظ (الخاصة) خلال أسواق الأسهم والسندات ربما تخضع لانخفاض بنسبة حوالي 80\%.

كذلك استمرت تكلفة الإرسال متجاوزة هدف 3)SDG) وكذلك بالنظر إلى الاختلالات الحادثة بالخدمات المتعلقة بالتحويلات برغم الاستخدام المتزايد للخدمات الرقمية والمنافسة المتزايدة من الركال قطاع الأعمال والحكومة في الدول المستقبلة.

وكما أشير سابقاً فإن متوسط التكلفة العالمية انخفضت من 6,9\% في الربع الأول من 2019

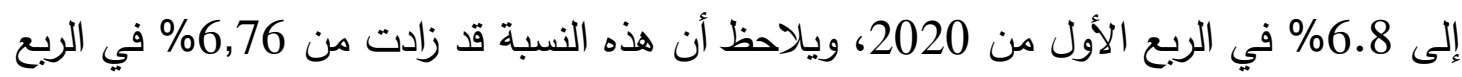
الأول من 2019 إلى 7\% بالنى الأنسبة لمجموعة دول MENA (الشرق الأوسط وشمال أفريقيا).

ووفقاُ لقاعدة بيانات البنك الدولي تصدرت مصر مجموعة دول الشرق الأوسط وشمال أفريقيا من حيث تدفق التحويلات إلى الداخل، حيث حصلت مصر على ما قيمته 26,8 مليار دولار تليها

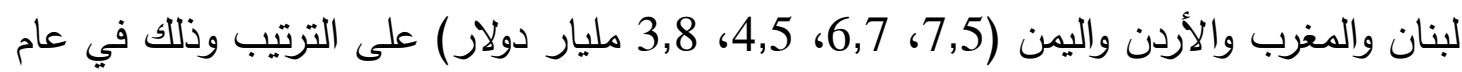

وهذه التدفقات مثلت ما نسبته 8,9\% من GDP خلال 2019 مقابل 12.7\%، 5,9\%، 10.2\%،

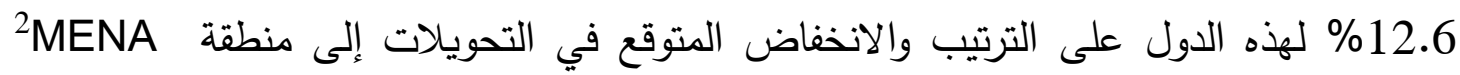

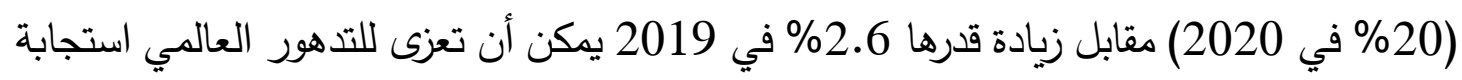

Word Bank Group, op. cit, pp.8-9 1

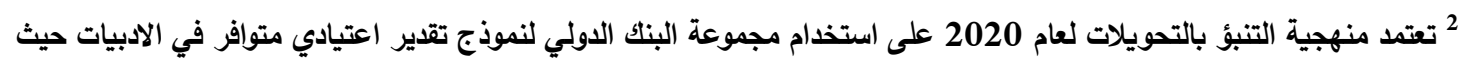

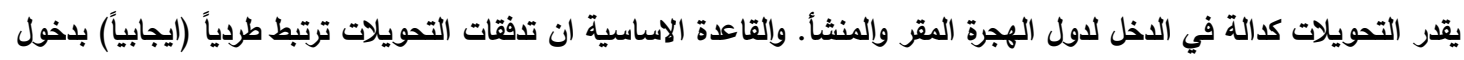

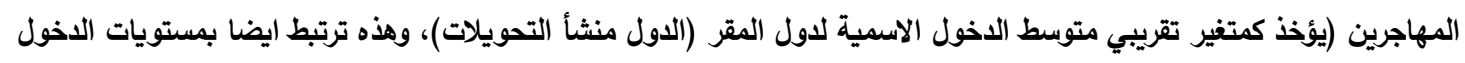

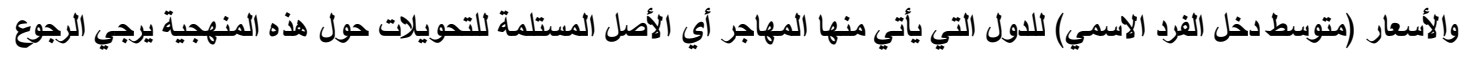
World Bank Group,op.cit, Appendix : Data Notes and Methodologies for forecasting - 
لتداعيات فيروس كورونا ولتأثير الانخفاض في أسعار النفط في دول مجلس التعاون الخليجي.

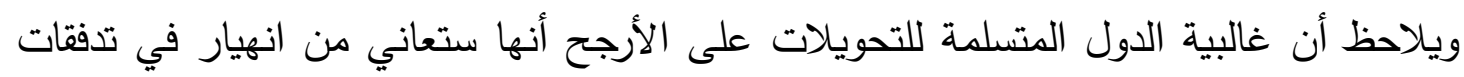

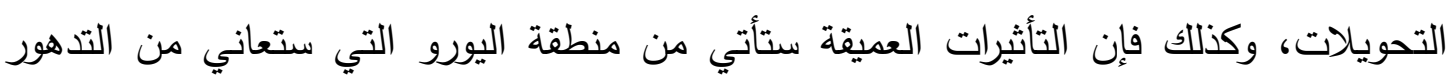

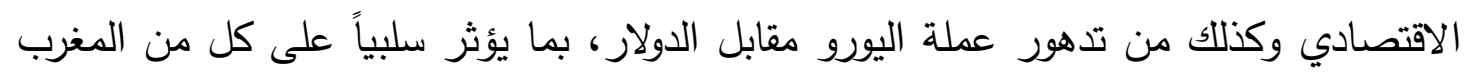

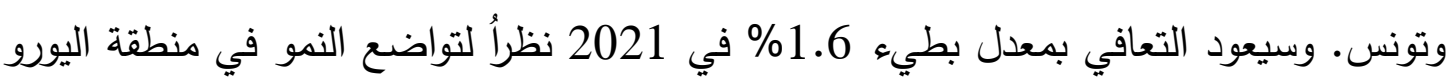
وفي ظل ضعف التدفقات من دول مجلس التعاون الخليجي.

علي الجانب الآخر يشير تقرير لصندوق النقد الدولي 1 أن كوفيد 19 يمثل تهديداً صريحاً لمستوردي

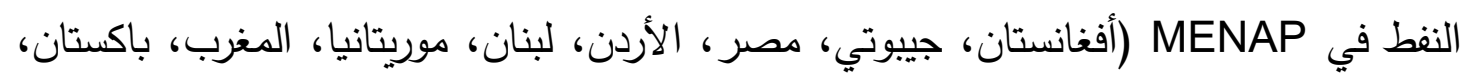

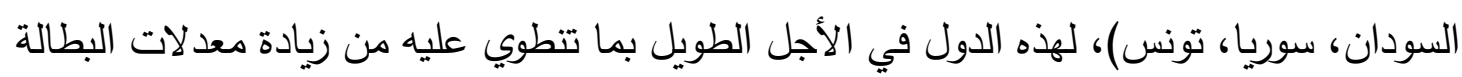

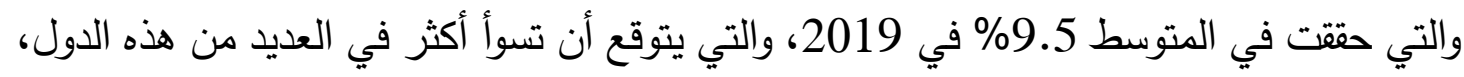

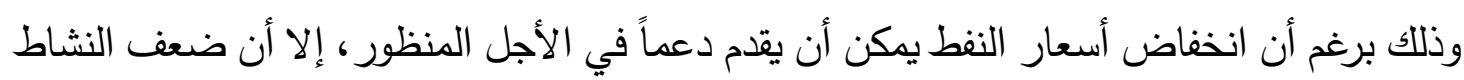

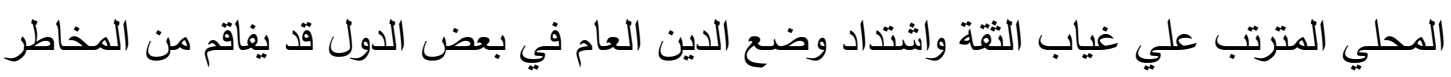

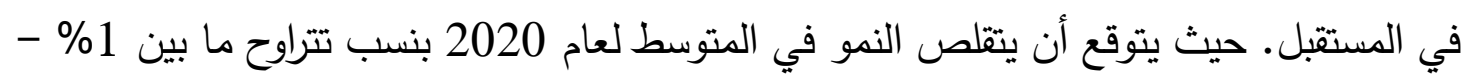

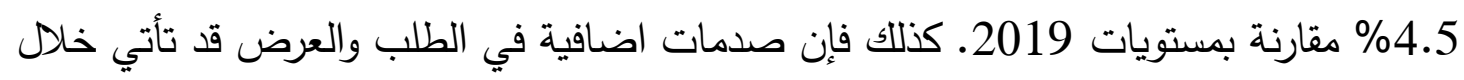

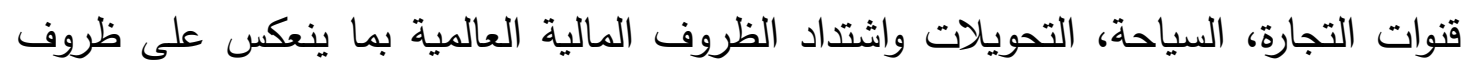

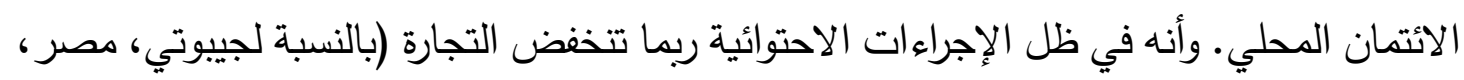

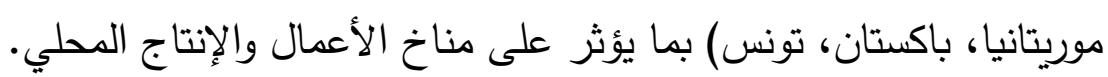
وتعتمد هذه الدول المستوردة للنفط كثيراً علي الواردات تلبية لاحتياجات الطلب المحلي والصادرات

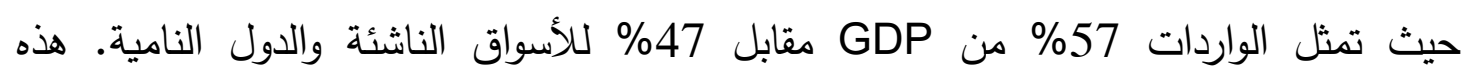
الاختلالات المتوقعة في المعروض من سلع الاستهلاك والتدهور في العملة يمكن أن يدفع الاسعار

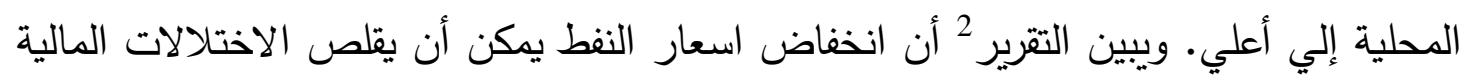

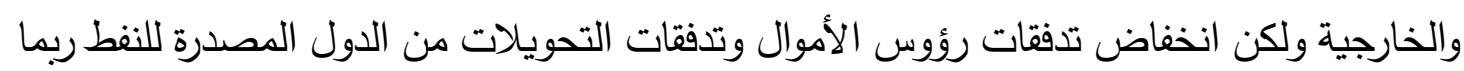
IMF (2020) The Regional Economic outlook: Middle East and Central ASIA, update. ${ }^{1}$ IMF (2020), ibid, pp.16-19 2

\begin{tabular}{|c|c|c|c|c|}
\hline $\begin{array}{l}\text { توزان الحساب الجارى من GDP } \\
\text { GP }\end{array}$ & التوازن المالى & معدل التضخم & معدل النمو & السنة \\
\hline$\%(4.3)-$ & $\%(7.7)-$ & $4.9 \%$ & $2 \%$ & 2020 \\
\hline$\%(4.5)-$ & $\%(5.9)-$ & $7.2 \%$ & $2.8 \%$ & 2021 \\
\hline
\end{tabular}


يؤثر أيضاً علي النشاط الاقتصادي. ولكن في عام 2014 عندما انخفضت أسعار النفط إلى النصف استطاعت دول MENAP المستوردة تحسين موازينها المالية بنسبة 0.6\% من GDP وحساباتها الجارية بنسبة 0.9\% من GDP ومع ذللك انخفضت كل من نسبة التحويلات والاستثمار المباشر بنسبة 0.3\%، 1\% من GDP على الترتيب. وتوقع التقرير أن تتحسن موازين الحساب

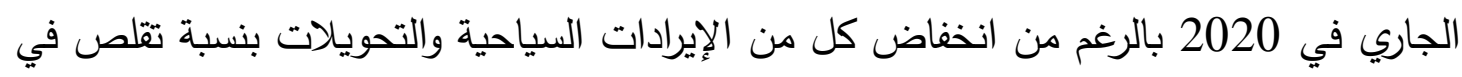

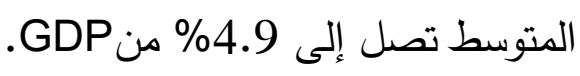

ويشير تقرير آخر لـ IMF أن منطقة MENA قد تعرضت لتراجع في تدفقات الحافظة يقترب من

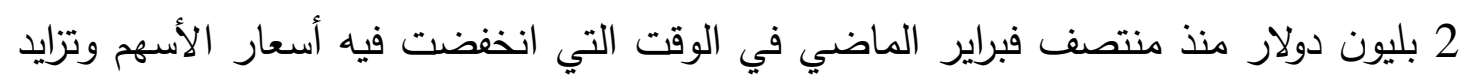

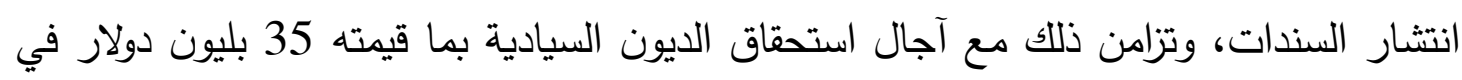

وتتتبأ إحدى دراسات صندوق النقد الدولي2 بأن أكثر القطاعات تضرراً من تفشي الفيروس هما:

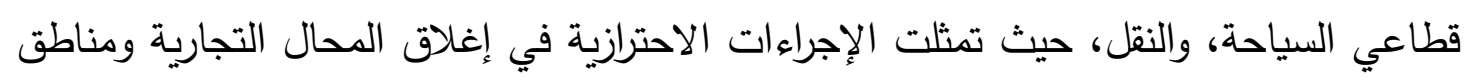

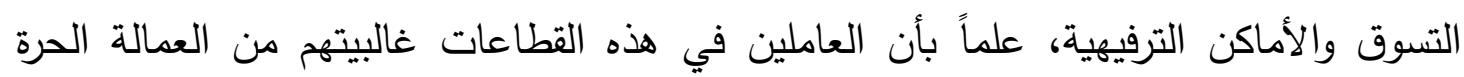
والمؤقتة، ومن ثم فإن تداعيات فيروس كورونا تنعكس على سوق العمل كونها ستؤدى إلى تسريح

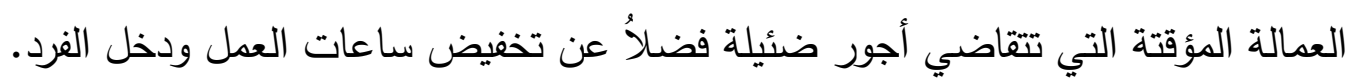
وعليه سوف يكون مستوى تأثر العمالة الماهرة في الوظائف الدائمة في القطاعين العام والخاص

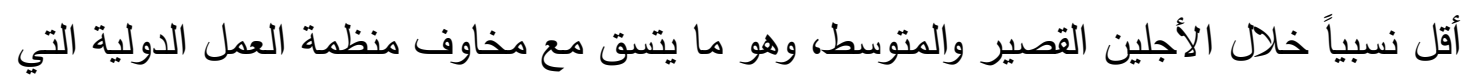
أشارت إلى أن التداعيات الاقتصادية للفيروس قد تتسبب في فقدان 25 مليون وظيفة في العالم

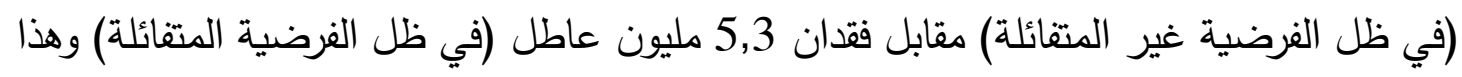

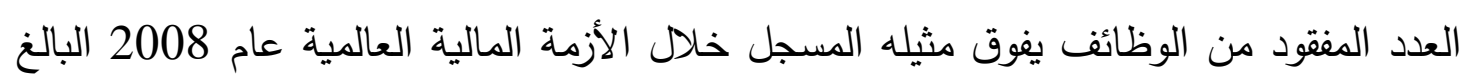
3. 22 مليون وظيفة المغد من المدنة 2- قنوات انتقال تأثير انتشار فيروس كورونا على تحويلات المصريين العاملين بالخارج

World Economic Forum, Emerging Priorities and Principles for Managing the Global 1 Economic Impact of COVID-19,Chief Economists oat hook, April 2020 .,P.10 2 ألوليد احد طلحة، التداعيات الاقتصادية لثيروس كورونا المستجد على الدول العربية، صندوق النقد العببي، أبريل 2020، ص 
يحددها تقرير صندوق النقد العربي في قناة الطلب الخارجي، الأسعار العالمية للنفط، تدفقات

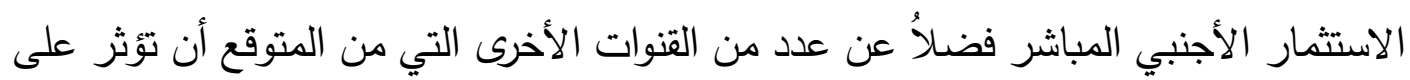

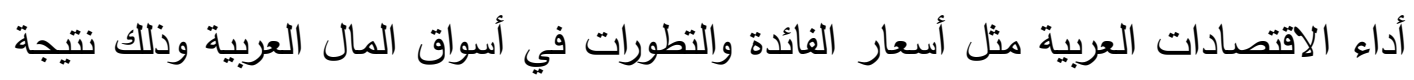
ارتباط عدد من العملات العربية بالدولار أو بوحدة حقوق السحب الخاصة أو بسلة من العملات التهات

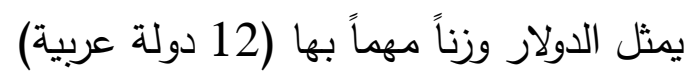

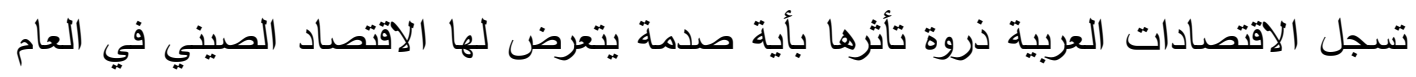

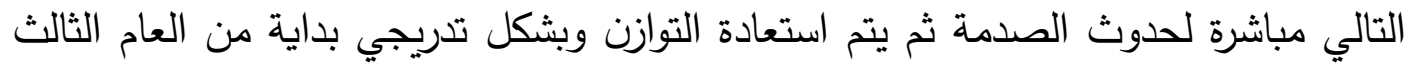

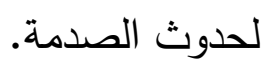

تأثر صادرات الدول العربية بتراجع محتمل للطلب العالمي بما لا يقل عن 50\% وذللك بما يشمل كل من الدول العربية المصدرة للنفط والمستوردة له، وهو ما سوف ينعكس على مستويات

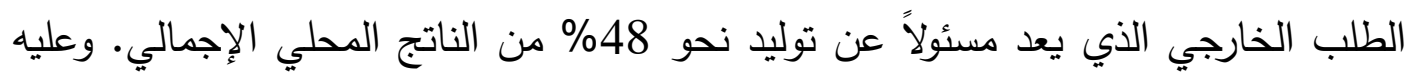
سوف تتأثر الاقتصادات العربية بتباطؤ محتمل في الطلب لاى عدد من شئل شركائها التجاريين

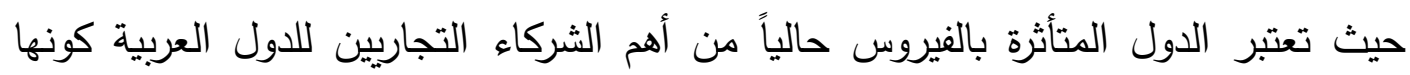
تستوعب 65\% من الصادرات العربية.

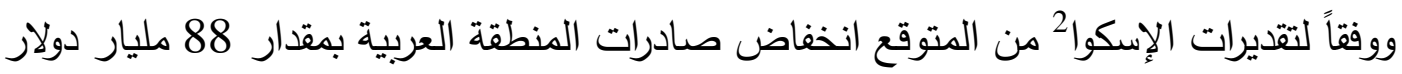

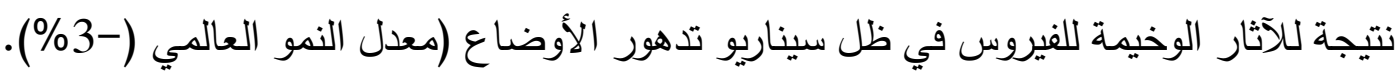

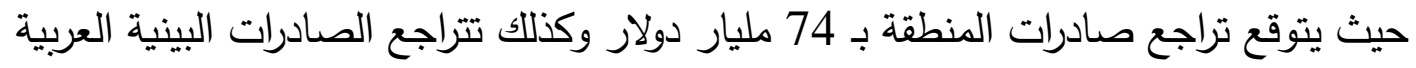

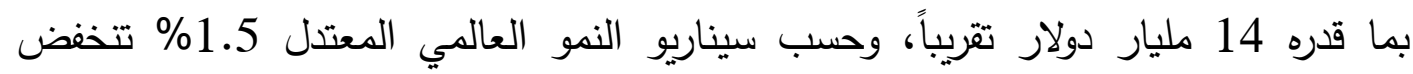

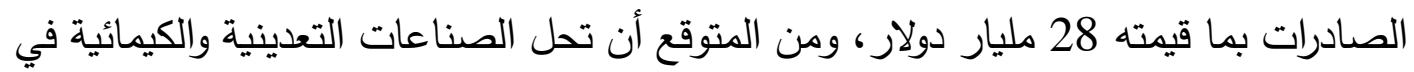

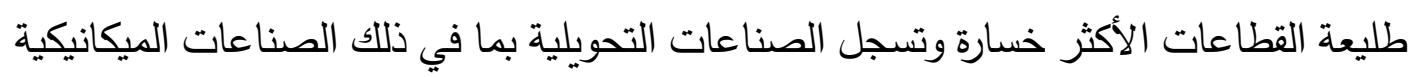
والكهربائية نحو 13\% من إجمالي انخفاض الصادرات أي أنها ثاني أكثر القطاعات تضرراً.

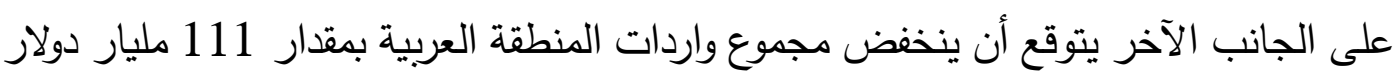

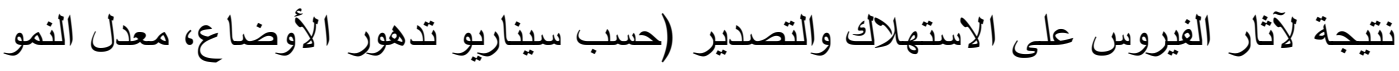

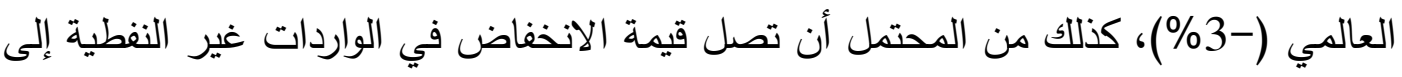

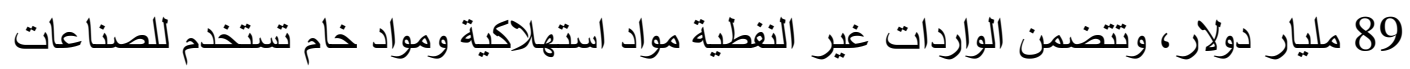

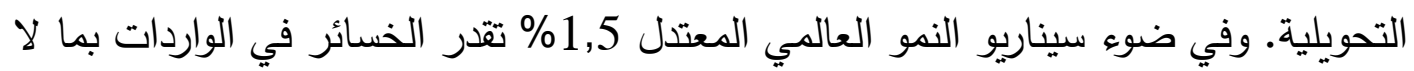

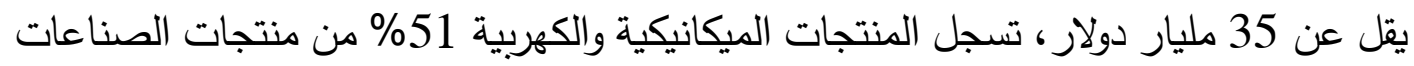

E/ESCA/ 2020 / Policy الاسكوا، آثار جائحة كوفيد -19 على الاقتصادات العربية: (التجارة والاستثمار الاجنبي المباشرئ 
التحويلية من إجمالي الانخفاض في الواردات وتسجل الصناعات الكيمائية نحو 17\% من إجمالي انخفاض الواردات - أي أنها ثاني أكثر الصناعات تضررأ في المنطقة العربية.

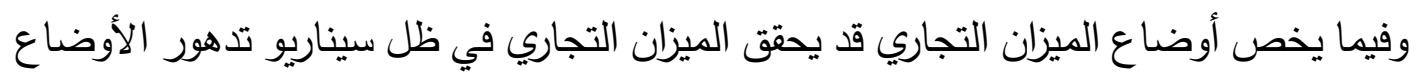

صافي موجب قدره 12 مليار دولار • وفي ظل سيناريو النمو المعدل (+) 3 مليار دولار .

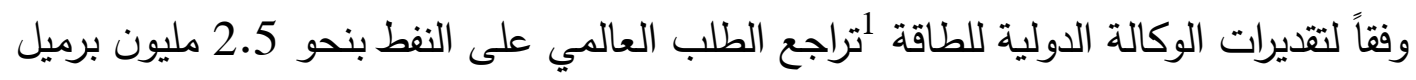

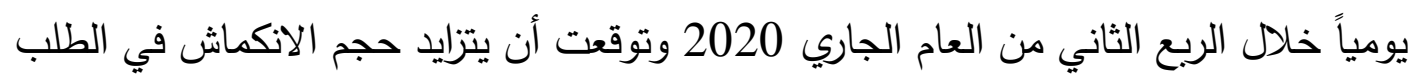
إلى ما قد يصل إلى 20\% أو نحو 20 مليون برميل يومياً خلال أسوأ فترات الأزمة. وإذا لإنا

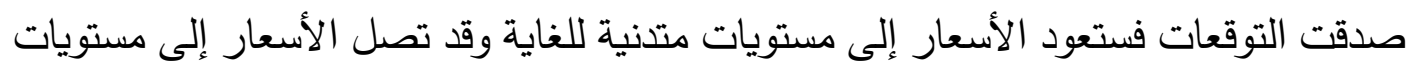

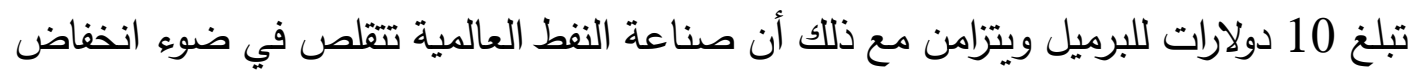
العائد علي رأس المال المستثر ، ولذلك ستتوسع فقط الشركات الأقوى على الاستمرار .

يوضح جدول (1) تطور أسعار النفط العالمية خلال الفترة 2003 - الثهور الأولي (الربع الأول

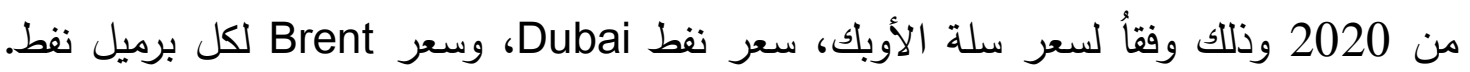
والملاحظ بأن OPEC Basket يمثل متوسط مرجح لأسعار الخامات البترولية التي ينتجها أعضاء

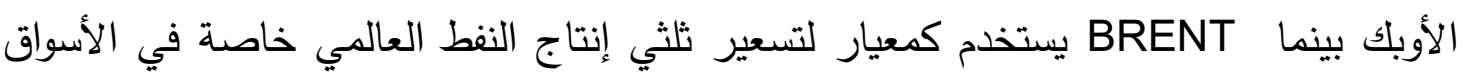
الأوروبية والأفريقية... ويتبين بصفة عامة الاتجاهات الهبوطية لأسعار النفط خلال السنوات (2014- 2017) ثم التحسن في الأسعار في عام 2018 ثم معاودة الهبوط في 2019 والربع الأول في 2020

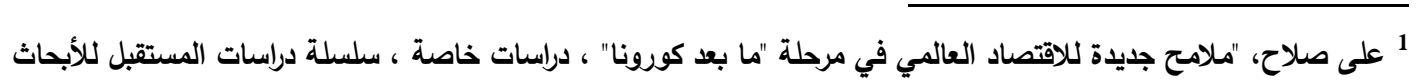

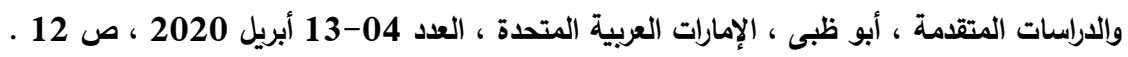


جدول (1) تطور أسعار النفط العالمي خلال الفترة (2003-2020)

\begin{tabular}{|c|c|c|c|c|}
\hline $\begin{array}{l}{ }^{(2)} \text { Brent } \\
(\$ / b)\end{array}$ & $\begin{array}{c}\text { Dubai }(\mathbf{b} / \$) \\
(\$ / \mathbf{b})\end{array}$ & $\begin{array}{c}\text { Changes } \\
\text { (year to year) }\end{array}$ & $\begin{array}{c}{ }^{\text {(1OPEC Basket }}(\$ / \mathrm{b}) \\
\end{array}$ & السنوات \\
\hline 28.9 & 26.73 & - & 28.1 & 2003 \\
\hline 38.3 & 33.45 & 28.4 & 36.07 & 2004 \\
\hline 54.43 & 49.29 & 39.9 & 50.47 & 2005 \\
\hline 65.39 & 61.43 & 21.0 & 61.08 & 2006 \\
\hline 72.69 & 68.36 & 13.1 & 69.08 & 2007 \\
\hline 97.63 & 93.77 & 43.9 & 99.4 & 2008 \\
\hline 61.86 & 61.75 & -39.8 & 59.85 & 2009 \\
\hline 79.63 & 78.06 & 29.4 & 77.45 & 2010 \\
\hline 110.93 & 106.03 & 38.7 & 107.46 & 2011 \\
\hline 111.96 & 108.9 & 1.9 & 109.45 & 2012 \\
\hline 108.85 & 105.43 & -3.3 & 105.87 & 2013 \\
\hline 98.93 & 96.65 & -9.0 & 96.29 & 2014 \\
\hline 52.37 & 51.17 & -48.6 & 49.49 & 2015 \\
\hline 44.04 & 41.2 & -19.6 & 39.8 & 2016 \\
\hline 54.39 & 53.11 & 29.7 & 51.62 & 2017 \\
\hline 71.07 & 69.15 & 37.1 & 70.75 & 2018 \\
\hline 64.03 & 63.17 & -9.8 & 63.82 & 2019 \\
\hline 63.6 & 63.8 & 2.0 & 65.09 & يناير 2020 \\
\hline 55.0 & 54.5 & -14.7 & 55.49 & فبراير 2020 \\
\hline 33.0 & 33.8 & - & - & مارس 2020 \\
\hline
\end{tabular}

- بيانات مجمعة من التقارير السنوية لمنظمة الأوبك المتاحة على الرابط التالي:

(10/5/2020). https://www.opec.org/opec_web/en/publications/338.htm

- بيانات إحصائيات الانكتاد، الأسعار السلعية الثهرية والسنوية متاحة على الرابط التالي:

https://unctadstat.unctad.org/wds/ReportFolders/reportFolders.aspx (10/5/2020).

وبالنسبة لقناة الاستثمار الأجنبي المباشر يقدر تقرير الإسكوا تراجعاً بمقدار 17.8 مليار

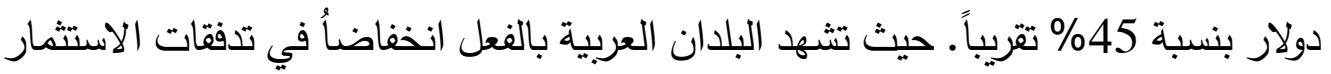

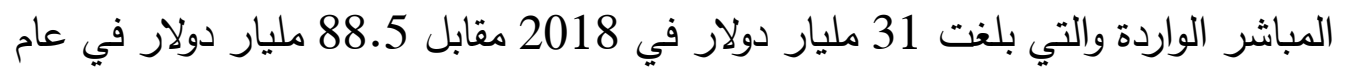

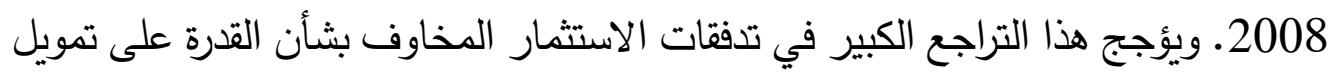
المشاريع في المنطقة العربية في مجال الطاقة والبتروكيماويات.

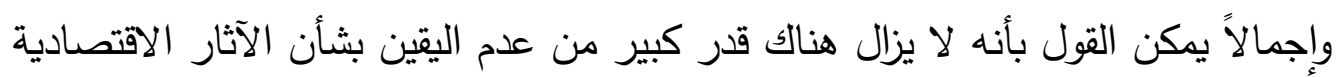

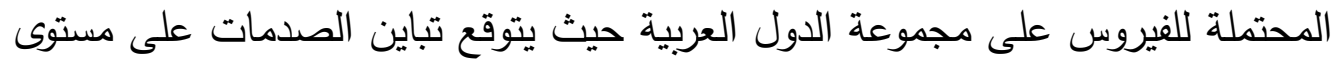

OPEC Basket ${ }^{1}$ مزبع ${ }^{2}$ مزيج نفطي من 15 حقلا مختلفًا في منطقتي برنت وتينيان (بعضها يقع في الملكة المتحدة والبعض الآخر في النرويج) 


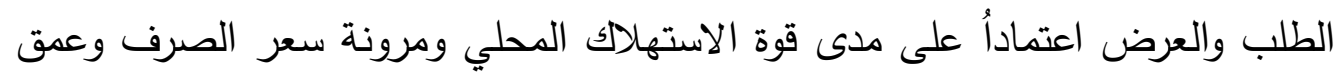

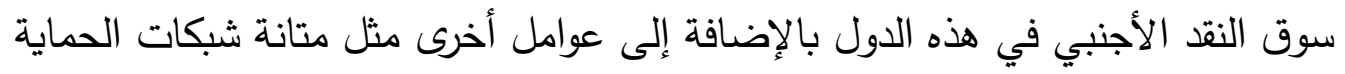

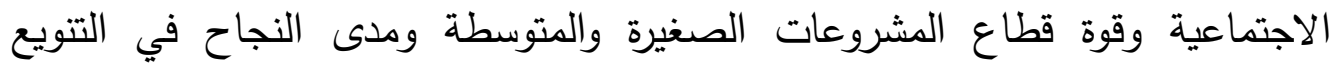
الاقتصادي والمضي قدماً في تتفيذ الاستراتيجيات القطرية 2030.

\section{3-خصائص الهجرة وتحويلات العاملين المصريين}

وفقاً لمفهوم الهجرة المؤقتة تتمثل اهم المؤشرات العامة بالاعتماد على إجمالي التصاريح الصادرة

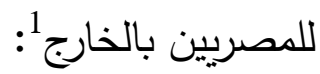

بلغت أعداد التصاريح الصادرة للمصريين للعمل بها إلى 1078254 في 2018 بنسبة انخفاض قدرها (18.0\%). وقد جاءت آداءت المجموعة العربية بعدد 1046399 تصريح تمثل 97\% من إجمالي التصاريح الصادرة 2018 بينما سجلت الدول الأوروبية نسبة 1.9\% من الإجمالي في نفس السنة.

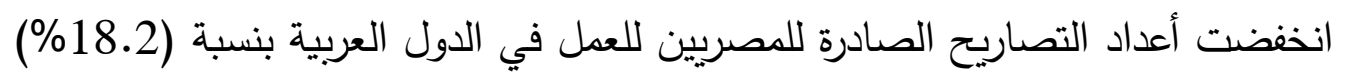

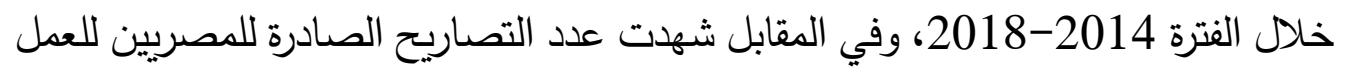
في الدول الأوروبية بنسبة انخفاض أكبر (29.7\%) خلال نفس الفترة.

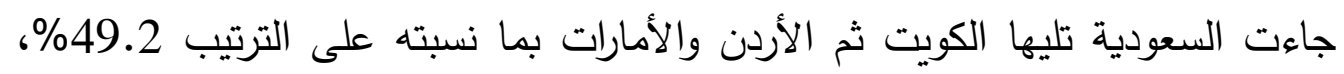
22.1\%، 12.0\%، 9.6\% في عام 2018 من إجمالي تصاريح العمل، بينما تركزت

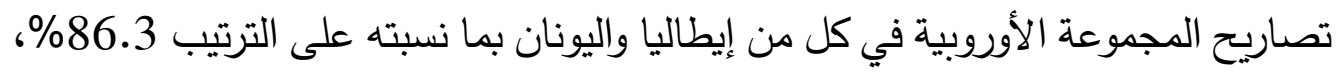

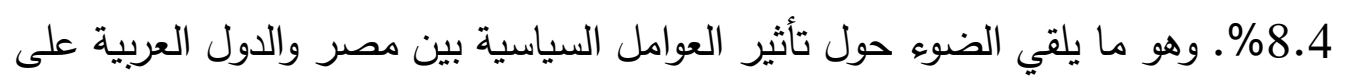
التوزيع الجغرافي لمصادر التحويلات.

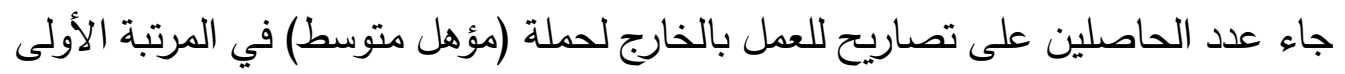

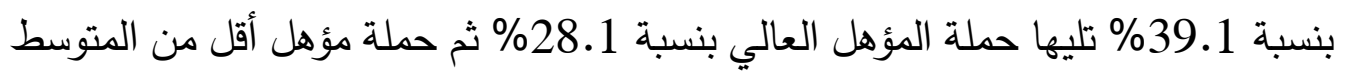
وبدون مؤهل على المركز الثاني بنسبة 27.6\% (جدول 23)، وفيما يخص مجموعة الدول

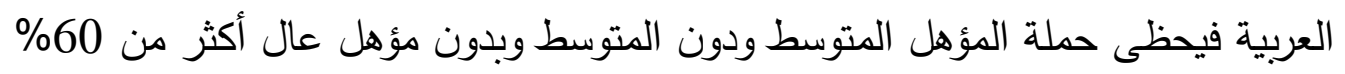
من حملة التصاريح في 2018. ونفس النتيجة تسري على الحاصلين على تصاريح للعمل

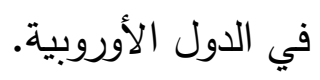

1 الجهاز المركزي للتعبئة العامة والاحصاء، النشرة السنوية لتصاريح العمل الصادرة للمصريين للعمل بالخارج عام 2018، اصدار اغنس 2019، جدول رقم (1)، ص 9. 
وللأسف لا توفر نشرة الجهاز المركزي للتعبئة العامة والإحصاء توزيع تصاريح العمل

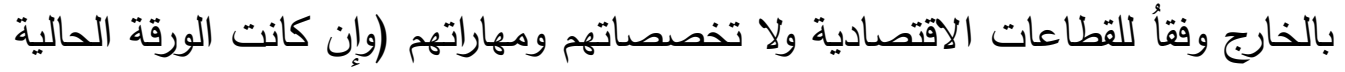
تميل إلى استخدام المستوى التعليمي كمؤشر تقريبي لمستويات المهارة).

جدول (2)

إجمالي تصاريح العمل الصادرة للمصريين للعمل بالخارج طبقاً للحالة التعليمية ومجموعات الاول في الفترة من عام 2014 حتى عام 2018 والأوزان النسبية لكل مجموعة تعليمية

\begin{tabular}{|c|c|c|c|c|c|}
\hline عدادجم\% & مؤهل اقل من مؤهل وبدون & مؤهل متوسط & مؤهل فوق المتوسط & مؤهل عالي & الحالة التعليمية \\
\hline 6141193 & 1697969 & 2444975 & 301436 & 1726813 & \\
\hline $100-$ & $(27.5)$ & (39.6) & $(4.9)$ & $(27.9)$ & \\
\hline $\begin{array}{c}5976670 \\
97.3 \\
(100.0)\end{array}$ & $\begin{array}{c}1663705 \\
(27.8)\end{array}$ & $\begin{array}{c}2336156 \\
(39.1)\end{array}$ & $\begin{array}{c}294452 \\
(4.9)\end{array}$ & $\begin{array}{c}1682357 \\
(28.1)\end{array}$ & مجموعة الدول \\
\hline $\begin{array}{c}120332 \\
2.0 \\
(100.0)\end{array}$ & $\begin{array}{l}27358 \\
(22,7)\end{array}$ & $\begin{array}{l}60293 \\
(50,1)\end{array}$ & $\begin{array}{l}4853 \\
(4.0)\end{array}$ & $\begin{array}{l}27828 \\
(23.1)\end{array}$ & مجموعة الدول \\
\hline 0.7 & - & - & - & - & أخرى \\
\hline
\end{tabular}

المصدر: النثرة السنوية لتصاريج العمل الصادرة للمصريين للعمل بالخارج عام 2018، الجهاز المركزي للتعبئة العامة

$$
\text { أما الإحصاء، إصدار أغسطس، فقد حسبت بمعرفة الباحث } 2019 .
$$

$$
\text { 3-3 اتجاهات التحويلات في مصر (2003-2020) }
$$

شهدت تدفقات التحويلات للعاملين المصريين جدول رقم (3) ارتفاعاً متزايدأ خلال السنوات 2004-2005 وحتى عام 2014-2015 وباستثاء السنة المالية التي تلت الأزمة المالية العالمية 2007-2008 والتي انعكست في انخفاض قيمة التحويلات في عام 2008-

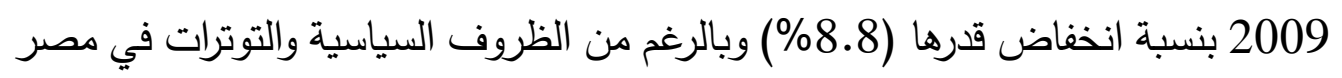

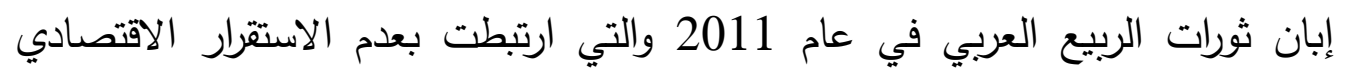

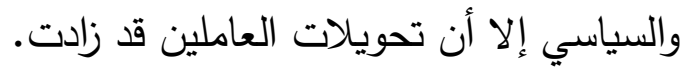
برز اتجاهاً متتامياً للتحويلات بنسبة 29\% بحلات بين السنتين 2009-2010، 2010-2011

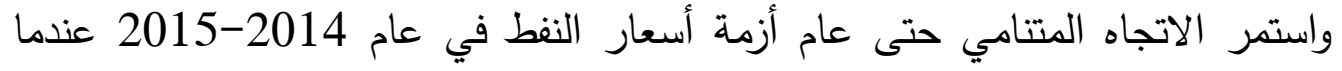
هبطت قيمة التحويلات بنسبة 11.4\% في 2015 -2016 ثم استمرت الزيادة في قيمة 
التحويلات من 17.1 مليار دولار في عام 2015-2016 حتى وصلت إلى 26.4 مليار

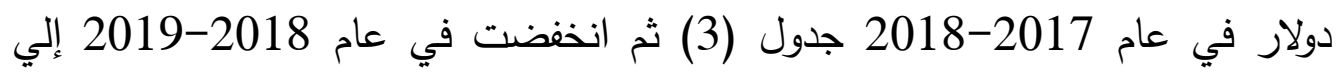
25.2 مليار بنسبة (4.5\%) تحت تأثير تصاعد حدة التوترات التجارية، تباطؤ النمو في

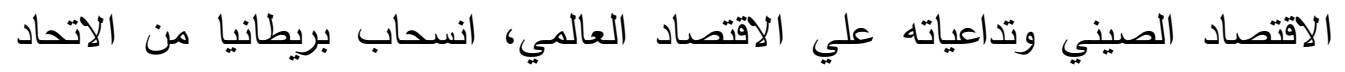

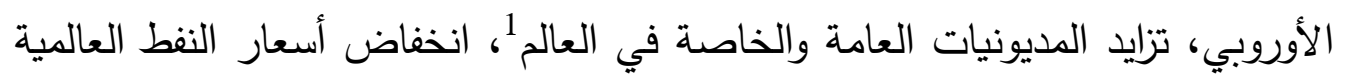

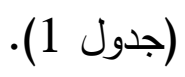

ومن الواضح أن عام تحرير سعر الصرف الأجنبي في مصر قد ساهم في إحداث قفزة في التحويلات في عام 2016-2017 حيث زادت قيمة التحويلات بنسبة 27.8\% استمرار اتجاه التزايد في قيمة تحويلات العاملين المصريين في الخارج خلال الربعين الأول

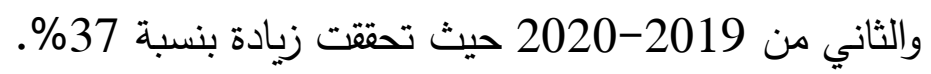

3-2 تعتبر تحويلات العاملين من اهم مصادر النقد الأجنبي في مصر:

حيث يوضح جدول (3) وشكل (2) تزايد الوزن النسبي للتحويلات من 13.0\% في 2004-

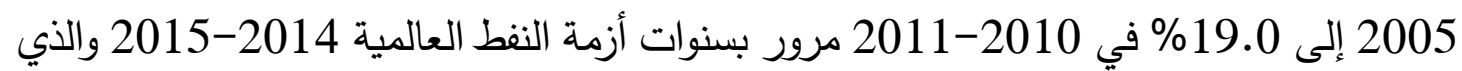
سجلت فيها حوالي 29\% من أهم موارد مصر من العملات الأجنبية (الصادرات، رسوم المرور

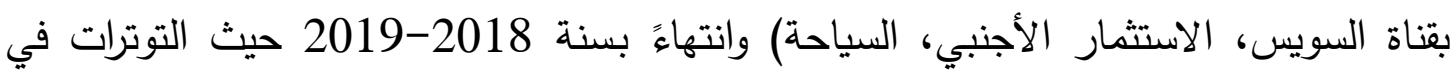
الاقتصاد العالمي والتي حقتت فيها حوالي 33\% من إجمالي موارد النقد الأجنبي.

\section{شكل(2) الأهمية النسبية لمصادر النقد الأجنبي خلال الفترة (2004-2020)}

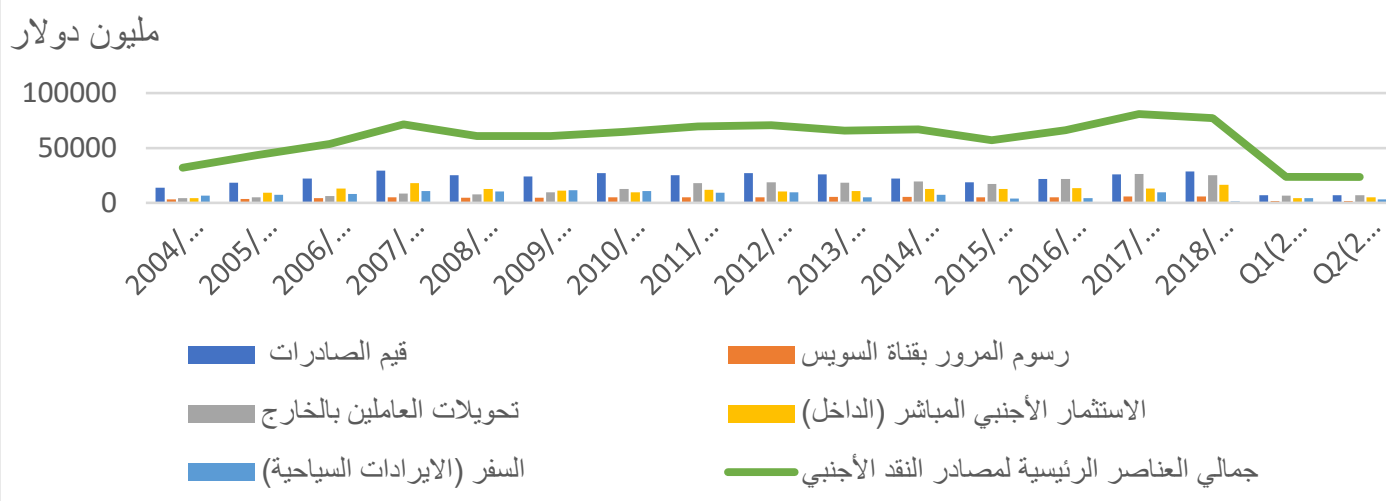

المصدر: بالاعتماد على بيانات الجدول رقم (3).

1 صندوق النقد العببي، تقرير آفاق الاقتصاد العببي، الإصدار العاشر، سبتمبر 2019 ص 9-12 - يوليو/ ديسمبر. 


\section{3-4 نسبة تفطية قيمة التحويلات لكل من الصادرات والواردات}

- - يوضح جدول (4) أن قيمة التحويلات قد قاربت قيمة الصادرات في السنوات التي أعقبت أزمة

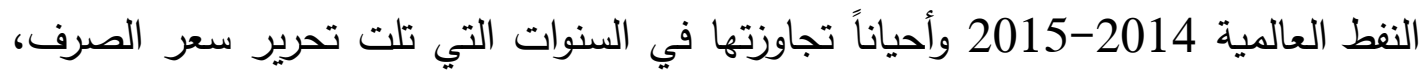
وأنه حتى في الربعين الأول والثامن من 2019-2020 قاهيان تجارتها فيت نفس مستوى الصادرات.

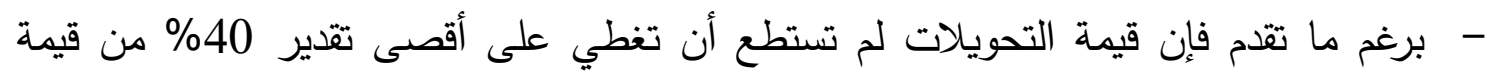

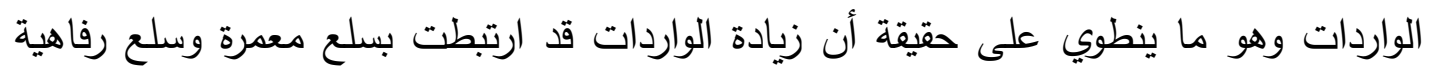

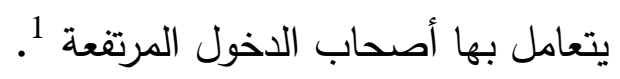
- - يتضح مما تقدم أن تحويلات العاملين المصريين في الخارج قد أصبحت أكبر مصدر للتمويل في مصر متجاوزة الاستثمار الأجنبي المباشر والإيرادات السياحية ورسوم المرور في فئناة

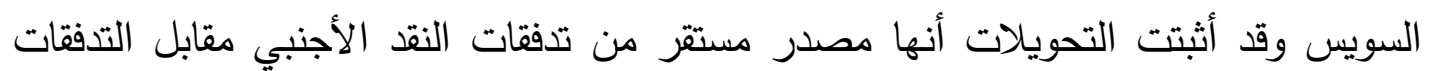

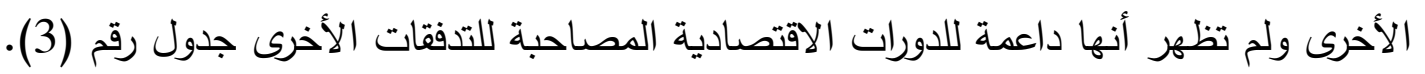
وبشكل عام يمكن النظر للتحويلات كآلية تأمين ذاتية للدول النامية (من بينها مصر ) من خلاد تمكنهم من تتويع مواردهم من مصادر التمويل الخارجي.

3-5 درجة تأثر تدفق تحويلات العاملين المصريين بالخارج بتطورات سوق النفظ العالمي

بالإضافة إلى ما تم الإثارة إليه بخصوص التوزيع الجغرافي لمصادر التحويلات والتي توضح بجلاء استحواذ الدول العربية ممثلة (في السعودية والكويت والأردن والإمارات وقطر ) وكذللك إيطاليا واليونان علي نصيب سوق العمالة بالنسبة للمهاجرين المصريين كهجرة مؤقتة. يبين شكل (1) يبين درجة الارتباط بين تطور تدفق التحويلات وتطور أسعار النفط بدرجة ارتباط منخفضة 0.08

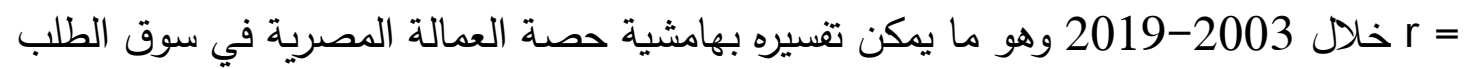
الخليجي، حيث خضعت التحويلات للاتجاهات طويلة الأجل في دول مجلس التعاون الخليجي

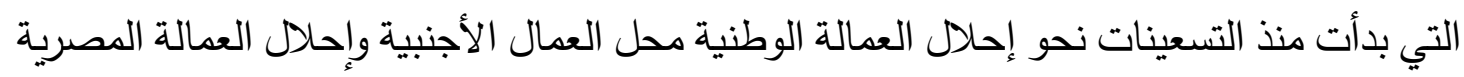

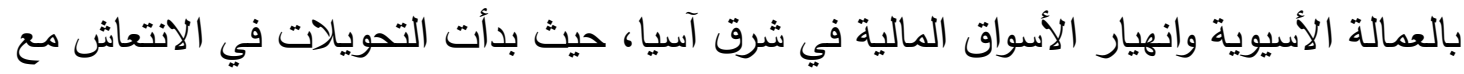
انتعاش أسعار النفط حتى النصف الأول من عام 2014، وقد خضعت الألئ التحويلات للعاملين المصريين لتأثير التغيرات في سياسة الصرف للدولار وخاصة بعد عام 2016 حيث لوحظ زيادة

1 فادية عبد السلام، التحويلات ودورها في النمو الاقتصادي (الفصل الثاثث) في معهل التخطيط القومي (تحرير) منافع واعباء التمويل

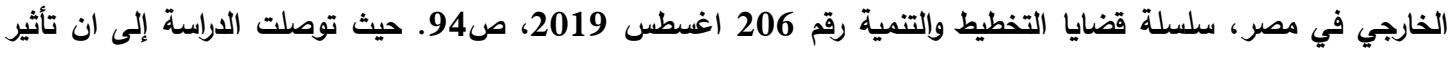

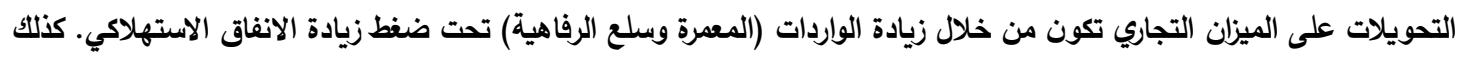

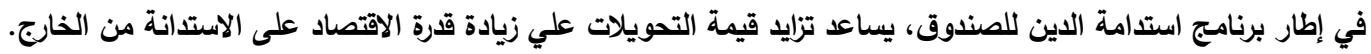


تدفقات تحويلات العاملين مع اقتراب سعر الصرف من السعر التوازني - أما علاقة الارتباط بين

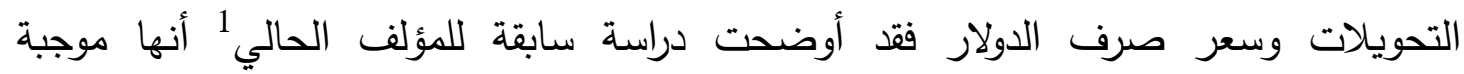

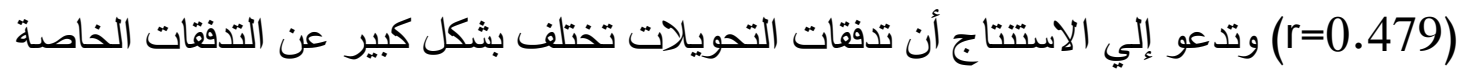
(أس المال الخاص أو الحافظة) من منظور الدافع أو الحافز (دوافع الايثار ودوافع الاستثمار)

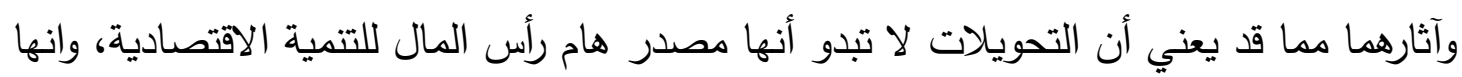

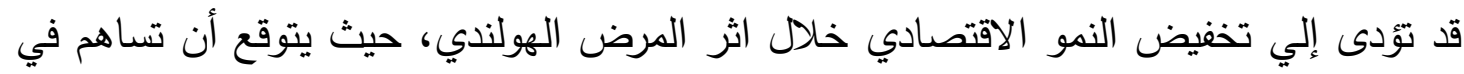

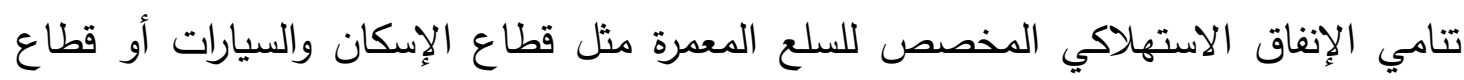
المفروشات، وحتى قواعد البيانات لا توفر تفصيلات للحكم علي درجة كفاءة تخصيص النقد الإندان

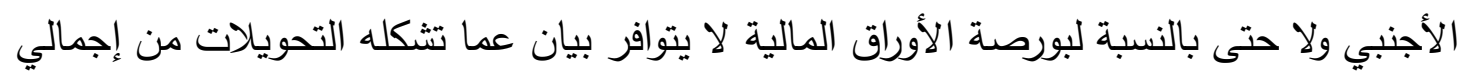

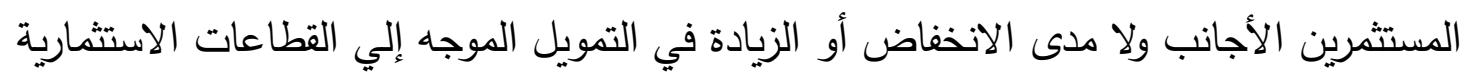

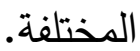

شكل (3): تطور أسعار النفط العالمية مقارنة بتطور تحويلات العاملين بالخارج خلال الفترة (2020-2003)

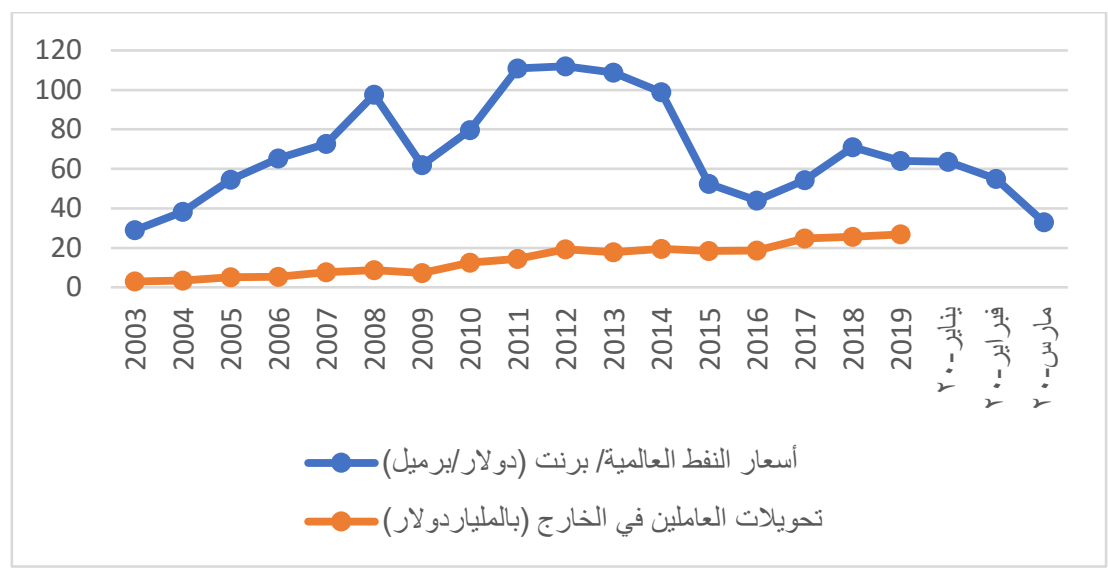

المصدر: بناء على بيانات الجدول رقم (1) والجدول رقم (2). > معامل الارتباط للمتغيرين خلال الفترة (2003-2003معامل التحديد للمتغيرين خلال الفترة (2003-2019) =

1 فادية عبد السلام، المرجع السابق، ص صإمبام 102-103.

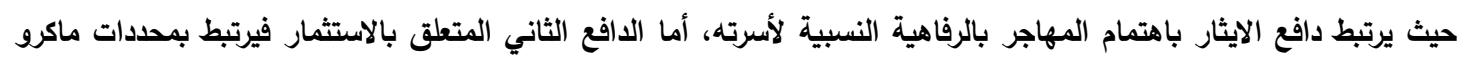

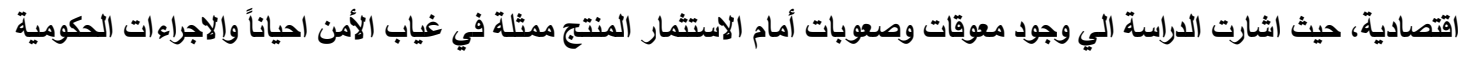

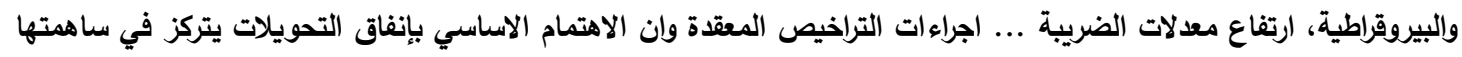
في تمويل المصروفات الاساسية، تمويل شراء العقارات والاستثمار في الاعمال الصغيرة وخلافه. 


\section{جدول (3) تطور قيم المصادر الرئيسية للنقد الأجنبي}

(القيم: بالمليون دولار) (الجيم)

\begin{tabular}{|c|c|c|c|c|c|c|c|}
\hline $\begin{array}{c}\text { النسبني } \\
\text { اللتحويلات } \\
\text { (\%) }\end{array}$ & 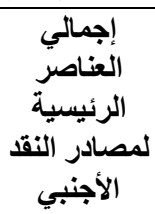 & 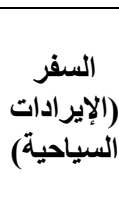 & الأجنبتمار & تالخاملين & رسوم المرورة & الصادرات & السنوات \\
\hline 13.52 & 32034 & 6429.8 & 4134.5 & 4329.5 & 3306.8 & 13833.4 & $2004 / 2005$ \\
\hline 11.60 & 43380.6 & 7234.6 & 9097.9 & 5034.2 & 3558.8 & 18455.1 & $2005 / 2006$ \\
\hline 11.75 & 53775.4 & 8183 & 13084.3 & 6321 & 4169.6 & 22017.5 & $2006 / 2007$ \\
\hline 11.94 & 71698.9 & 10826.5 & 17802.2 & 8559.2 & 5155.2 & 29355.8 & $2007 / 2008$ \\
\hline 12.79 & 61018.9 & 10487.6 & 12836.1 & 7805.7 & 4720.6 & 25168.9 & $2008 / 2009$ \\
\hline 16.06 & 60742.7 & 11591.3 & 11008.1 & 9753.4 & 4516.8 & 23873.1 & $2009 / 2010$ \\
\hline 19.43 & 64801.1 & 10588.7 & 9574.4 & 12592.6 & 5052.9 & 26992.5 & $2010 / 2011$ \\
\hline 25.88 & 69437.7 & 9419 & 11768.1 & 17970.9 & 5207.8 & 25071.9 & $2011 / 2012$ \\
\hline 26.40 & 70713.3 & 9751.8 & 10273.6 & 18668 & 5031.8 & 26988.1 & $2012 / 2013$ \\
\hline 28.13 & 65839.5 & 5073.3 & 10855.8 & 18518.7 & 5369.1 & 26022.6 & $2013 / 2014$ \\
\hline 28.91 & 66858.4 & 7375.4 & 12546.2 & 19330 & 5361.7 & 22245.1 & $2014 / 2015$ \\
\hline 29.86 & 57199.8 & 3767.5 & 12528.7 & 17077.4 & 5121.6 & 18704.6 & $2015 / 2016$ \\
\hline 32.94 & 66235.6 & 4379.7 & 13366.1 & 21816.3 & 4945.3 & 21728.2 & $2016 / 2017$ \\
\hline 32.63 & 80894 & 9804.3 & 13163.1 & 26392.9 & 5706.7 & 25827 & $2017 / 2018$ \\
\hline 32.65 & 77027.6 & 1257.6 & 16393.5 & 25150.8 & 5730.7 & 28495 & $2018 / 2019$ \\
\hline 28.21 & 23796.2 & 4193.6 & 4261.9 & 6712.6 & 1507.3 & 7120.8 & $\begin{array}{c}2019 / 2020 \\
\text { (Q1) }\end{array}$ \\
\hline 29.54 & 23574 & 3056.1 & 4899 & 6963.9 & 1524.8 & 7130.2 & $\begin{array}{c}2019 / 2020 \\
(Q 2)\end{array}$ \\
\hline
\end{tabular}

المصدر: بيانات البنك المركزي المصري، البحوث الاقتصادية، بيانات السلاسل الزمنية، ميزان المدفوعات المصري،

الاستثمار الأجنبي المباشر ، متاحة على الرابط:

https://www.cbe.org.eg/_layouts/15/WopiFrame.aspx?sourcedoc=\{F32D82E4-41F4-44AF-

$(11 / 5 / 2020) . \quad$ 8DB7-3E0B24C76D99\}\&file=BOP-Annual.xIsx\&action=default https://www.cbe.org.eg/_layouts/15/WopiFrame.aspx?sourcedoc $=\{1$ E9AE085-55CD-4DA5-

BD91-

D4F81CCE70CB\}\&file=Net_Foreign_Direct_Investment_In_Egypt_(FDI)_by_country_Annual.xIs\% 20(1).xIsx\&action=default 


$$
\begin{aligned}
& \text { جدول (4) الوزن النسبي لتحويلات العاملين في الخارج } \\
& \text { من إجمالي قيم الصادرات والواردات } \\
& \text { خلال الفترة (2004-2020) }
\end{aligned}
$$

\begin{tabular}{|c|c|c|c|c|c|}
\hline 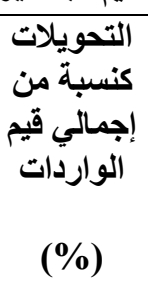 & 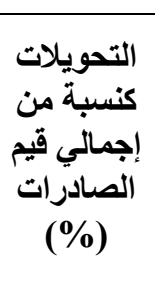 & تالخاملين & الوارديث & الصادرات & السنوات \\
\hline 17.90 & 31.30 & 4329.5 & 24192.8 & 13833.4 & $2004 / 2005$ \\
\hline 16.54 & 27.28 & 5034.2 & 30441 & 18455.1 & $2005 / 2006$ \\
\hline 16.50 & 28.71 & 6321 & 38308.1 & 22017.5 & $2006 / 2007$ \\
\hline 16.22 & 29.16 & 8559.2 & 52771.2 & 29355.8 & $2007 / 2008$ \\
\hline 15.51 & 31.01 & 7805.7 & 50342.2 & 25168.9 & $2008 / 2009$ \\
\hline 19.91 & 40.86 & 9753.4 & 48993.1 & 23873.1 & $2009 / 2010$ \\
\hline 23.28 & 46.65 & 12592.6 & 54095.5 & 26992.5 & $2010 / 2011$ \\
\hline 30.35 & 71.68 & 17970.9 & 59210.9 & 25071.9 & 2011/2012 \\
\hline 32.36 & 69.17 & 18668 & 57682.8 & 26988.1 & $2012 / 2013$ \\
\hline 30.77 & 71.16 & 18518.7 & 60181.9 & 26022.6 & $2013 / 2014$ \\
\hline 31.53 & 86.90 & 19330 & 61305.5 & 22245.1 & $2014 / 2015$ \\
\hline 29.76 & 91.30 & 17077.4 & 57387.7 & 18704.6 & $2015 / 2016$ \\
\hline 36.97 & 100.41 & 21816.3 & 59003 & 21728.2 & $2016 / 2017$ \\
\hline 41.83 & 102.19 & 26392.9 & 63103 & 25827 & $2017 / 2018$ \\
\hline 37.80 & 88.26 & 25150.8 & 66529.4 & 28495 & $2018 / 2019$ \\
\hline 42.21 & 94.27 & 6712.6 & 15904 & 7120.8 & Q1(2019/2020) \\
\hline 40.84 & 97.67 & 6963.9 & 17051 & 7130.2 & Q2(2019/2020) \\
\hline
\end{tabular}

القيم: بالمليون دولار

المصدر: بيانات البنك المركزي المصري، البحوث الاقتصادية، بيانات السلاسل الزمنية، ميزان المدفوعات المصري،

$$
\text { الاستثمار الأجنبي المباشر، متاحة على الرابط: }
$$

https://www.cbe.org.eg/_layouts/15/WopiFrame.aspx?sourcedoc $=$ \{F32D82E4-41F4(11/5/2020). 44AF-8DB7-3E0B24C76D99\}\&file=BOP-Annual.xIsx\&action=default 
6-3 الثواهد متباينة فيما يتعلق بتأثير التحويلات على النمو الاقتصادي

بعض الدراسات وجدت علاقة إيجابية بينهما ( حيث أن الهجرة المؤقتة ترتبط بمنافع أعلي للدولة المنشأ خلال العائد من رأس المال البشرى والمادي والاجتماعي حيث قدرت إحدى التقارير 1 أن هناك منافع محسوسة ومرئية لتدفقات التحويلات نحو الدول المتسلمة (المنشأ) خاصة الدول منخفضة ومتوسطة الدخل وقد قدرت التحويلات بما قيمته 539 مليار دولار في 2018 أي ما يتجاوز ثلاث مرات حجم مساعدات التتمية الرسمية وتدفقات الاستثمار المباشر كذلك فهي أكثر استقراراً وأقل تذبذباً من التدفقات الخاصة وتقوم التحويلات بوظيفة تمهيد الاستهلاك

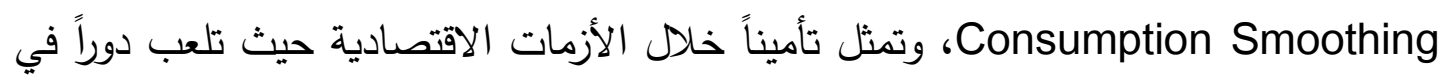
تحسين المستويات التغذوية وتقليص عمالة الأطفال في عدد من الدول النامية، فضلاً عن رفع مستوى الإنفاق علي التعليم والالتحاق بالدارس العليا، كذللك فإن الآثار الإيجابية للنمو خلال

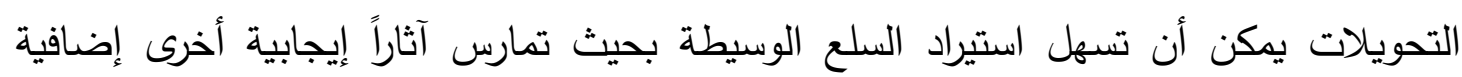

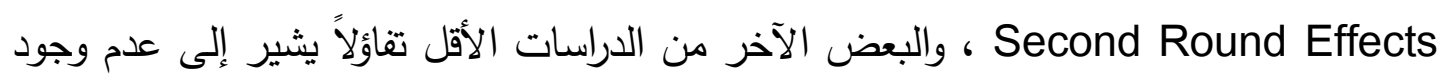
علاقة سببية بين التحويلات والنمو الاقتصادي بل ذهبت التحليلات إلى الإشارة إلى الآثار Non -Tradable التضخمية التي يحدثها علي أسعار السلع التي لا تدخل التجارة الدولية rate Appreciation of the Exchange وتصاحب كذلك بارتفاع (بمبالغة) في سعر الصرف والذي يقلص بدوره تنافسية الصادرات ( المرض الهولندي) السابق الإشارة إليه.

3-7 صدمات العرض والطلب التي تحدثها تداعيات فيروس كورونا على تدفق تحويلات المصريين بالخارج

من الصعوبة بمكان التتبؤ بتوقيت الانحسار والانتهاء من أزمة فيروس كورونا بالتعافي لأن ذلك مرتبط بتوقيت الوصول إلى لقاح للتحصين ضد الفيروس والذي يتوقع أن يكون في حدود من سنة

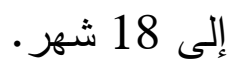


احتمالات تأثير فيروس كورونا على قيمة تحويلات المصريني تقوم على ثلاثة افتراضات رئيسية:

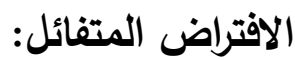

الاعتماد على ما حدث في عام أزمة أسعار النفط في عام 2014-2015 عندما هبطت قيمة تحويلات المصريين في عام 2015-2016 بنسبة 11.4\% وتكون السنة المرجعية هي 20182019 وذلك لتقدير التنبؤات المستقبلية خلال السنتين 2019-2020، 2020-2021. وهذا البديل يستتد على هامشية حصة الطلب على العمالة المصرية في كل من الأسواق الخليجية والأسواق الأوروبية وعليه يتوقع أن تصل قيمة التحويلات في 2019-2020 إلى 22.3 مليار دولار تحقق منها بالفعل 13.677 مليار دولار خلال الربعين (يوليه- ديسمبر) 2019-2020 إلا أن الربعين الآخرين يناير - فبراير - مارس - أبريل - مايو - يونية يتوقع أن يحققا خلالهم 8.6 مليار دولار • ويتوقع في ظل السيناريو المتفائل أن تستطيع العمالة المصرية العالقة العودة إلى مكان أعمالها وان يتم الاستغناء عن نسبة من العمالة الموجودة لدى أسواق العمل هنالك أي كان مستوى مهارتها.

أما تقديرات عام 2020-2021 فيقدر أن تصل إلى 19,7 مليار دولاز والأرجح أن تتعافي الاقتصادات العربية في مجلس التعاون الخليجي بفترة إبطاء لا تقل عن سنة عن تعافي الاقتصادات الرئيسية مثل الصين والاتحاد الأوروبي وشرق آسيا، ويدعم هذا السيناريو ما أشار إليه تقرير صندوق النقد العربي $2020{ }^{1}$ حول آفاق النمو الاقتصادي في السعودية من أنها تأثرت بتداعيات كورونا في قطاعات النقل والاتصالات وتجارة الجملة والتجزئة والمطاعم والفنادق والصناعات التحويلية الأخرى، يعكس جانب من هذا التأثير الانخفاض في إيرادات الحج والعمرة ( عدد المعتمرين في 2019 قد بلغ 18 مليون معتمر، 2.5 مليون حاج بإجمالي حجم القوى العاملة التي تخدم موسم الحج تقدر بنحو 350 الف وظيفة وان التوقعات تشير إلى المساهمة الفاعلة للقطاع الخاص غير النفطي في نمو الناتج المحلي خلال 2021 - أما الإمارات فقد تأثرت لديها قطاعات الضيافة والسياحة والنقل ومن المتوقع حدوث نمو في الربع الثاني 2020 بسبب النمو القوى لقطاع النفط. وقد يرتبط ذلك بإضافة ضغوط على المعروض من عنصر العمل في الداخل في ظل التوقعات بأن يتجاوز معدل البطالة متوسط 10\% لمجموعة دول (MENAP) مجموعة مستوردي النفط (معدل البطالة الحالي وفقاً لجهاز المركزي للتعبئة العامة والإحصاء هو 8\%). 


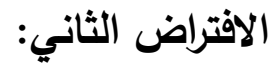

\section{السيناريو المتوسط}

ويستند على افتراض مجموعة البنك الدولي 2020 بان معدل نمو قيمة التحويلات لدول شمال أفريقيا والشرق الأوسط هو (-19,6\%) في عام 2020 وهذا مفاده أن قيمة تدفقات التحويلات فئل فئل

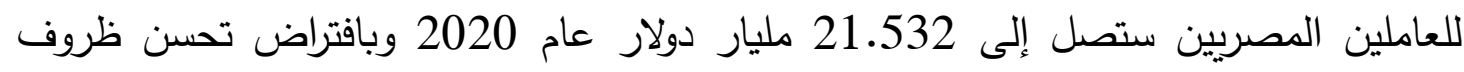

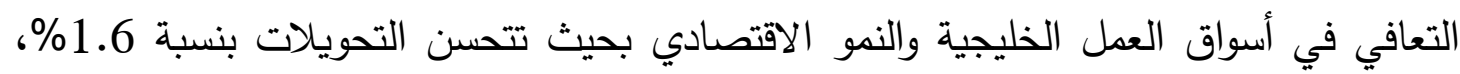
فيتوقع أن ترتفع قيمة التحويلات إلى 24.98 مليار دولار في 2021.

ويرتبط هذا السيناريو بشروط عدم رجوع العمالة العالقة والاستغناء عن بعض العمالة وعدم التجديد لأي عقود قديمة والتوقف عن قبول عقود جديدة لأول مرة. ويتوقع أن يضيف هذا السيناريو المزيد

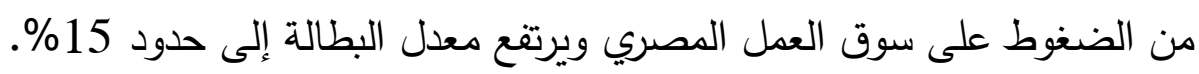

الافتراض الثالث

السيناريو المتثائم:

يقوم علي افتراض أنه في الصناعات ستتركز عمليات التسريح علي العمالة من المهاجرين من

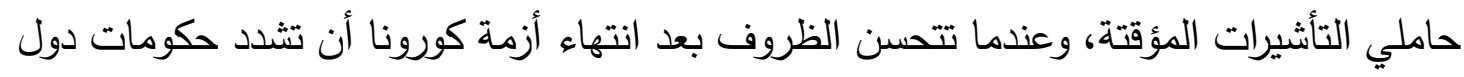
الخليج الشركات علي توظيف مواطنيها وخاصة من العمالة المهاجرة من ذوى المهارات المتدنية

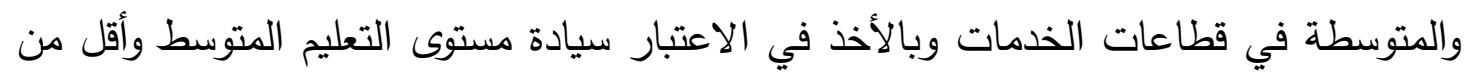
المتوسطودون المؤهل بما يتجاوز 60\% من العمالة في سوق الخليج جدول (2)، ولذا فالتوقعات

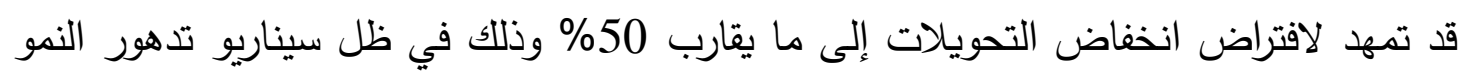

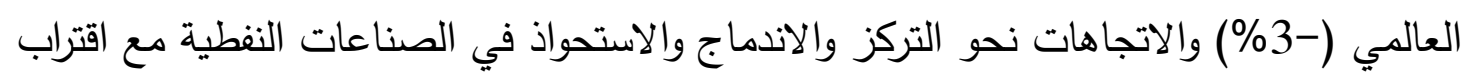

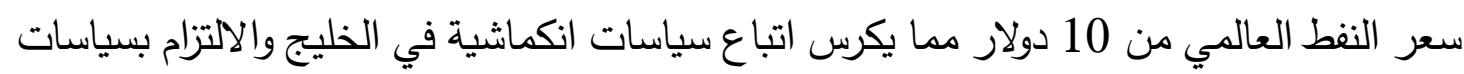
التقشف، وعليه فالقيم المتوقعة للتحويلات ستكون عند سريان هذه الثروط في حدود تتجاوز قليلا

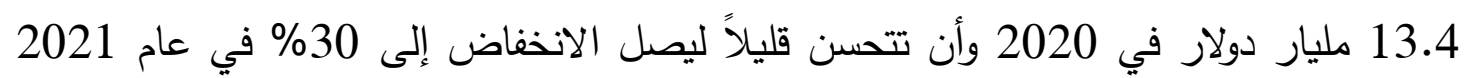
بحيث تسجل 18.75 مليار دولار • وفي ظل هذا السيناريو يتوقع مزيد من الارتفاع في معدل البطالة بحيث تقترب من 20\%. 
4- أثر انخفاض التحويلات على الاقتصاد المصري

على الرغم من برامج تقليص العمالة الأجنبية وسياسات توطين الوظائف التي تتبناها دول مجلس

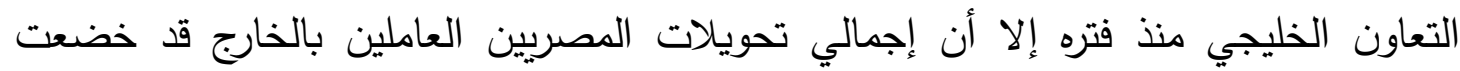

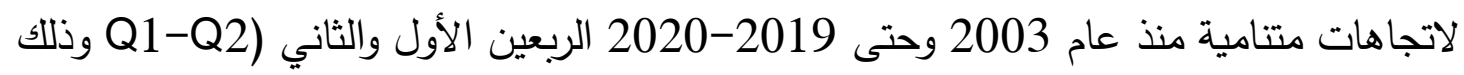

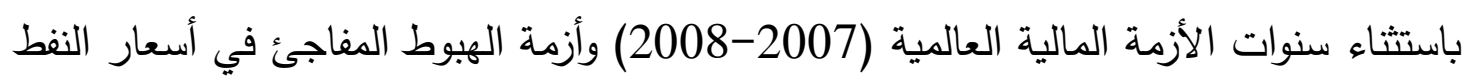
2015-2014

ومن المتوقع أن تتبنى هذه الدول العربية سياسات انكماشيه استجابة لتراجع أسعار النفط وخفض

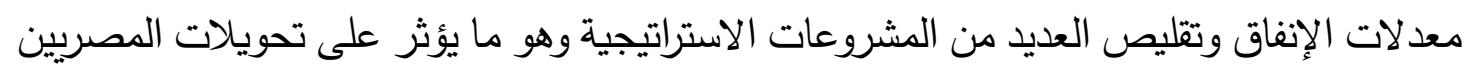
بالخارج في الفترة المقبلة (2020- 2021، 2021 - 2022) كما أوضحنا سلفاً.

ومن المؤكد أن أي انخفاض في تدفقات التحويلات ينطوي على تراجع أحد مصادر العملات

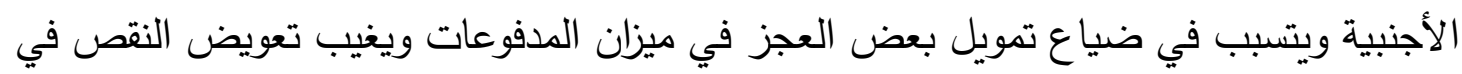

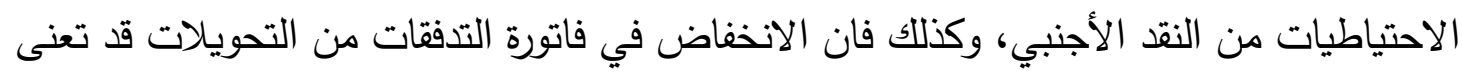

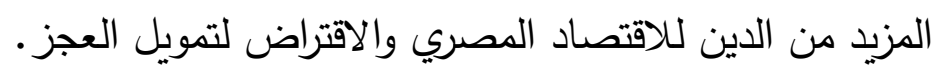

وفى ظل التشابكات المختلفة للتحويلات مع الإنفاق الاستهلاكي العائلي والادخار والاستثمار

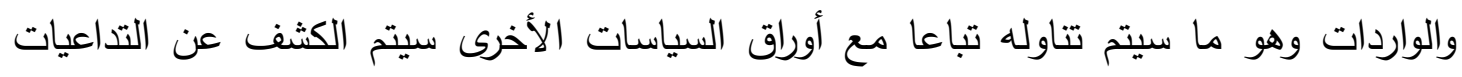
المباشرة وغير المباشرة لانتشار فيروس كورونا على كل متغيرات الاقتصاد الكلى.

نضف إلى ما سبق تأثير انخفاض التحويلات على الإيرادات الضريبية (دخول العاملين بالخارج،

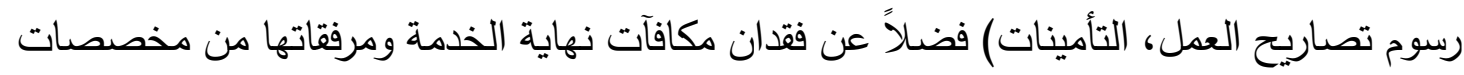
التعليم والرعاية الصحية.

قد يضاف إلى ما تقدم تداعيات انخفاض التحويلات وعلاقاتها بعمليات الاستغناء عن خدمات

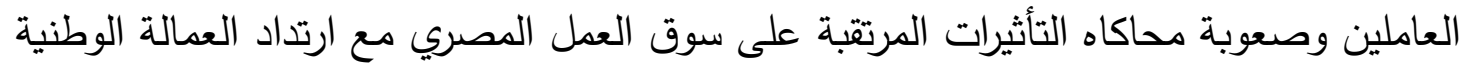

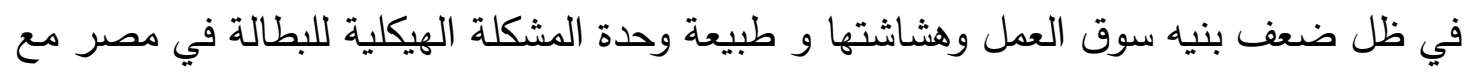
ضعف المنظومة التعليمية ومخرجاتها والتفاقم الرهيب في البطالة ومعدلاتها التي ربما تتجاون ولتها

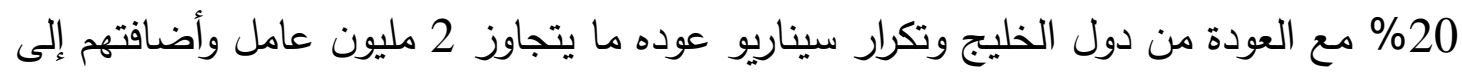
متطلبات سوق العمل في ظل غياب قواعد بيانات تفصيليه تربط بين مستويات التعليم والمهارة 
هل التوجهات المستقبلية التي المحت إليها الحكومة مؤخرا يمكن أن تغير من ملامح سوق العمل المصري ومعدل البطالة وهي نقطه سنتطرق لها في بعض الأجزاء اللاحقة؟.

\section{4-4 تدخلات على المستويات الوطنية والإقليمية على مستوى السياسات:}

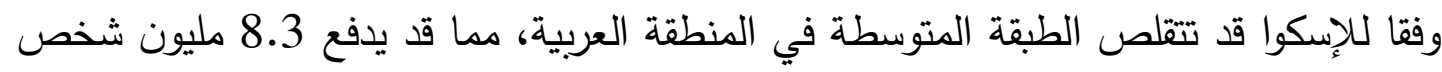

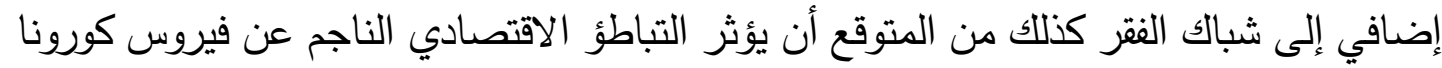
سلبا على الأجور وتدفق التحويلات ،وستكون التداعيات اكثر حده على الفئات الضعيفة سيما النساء والثباب والعاملين في القطاع غير المنظم الذين لا يستيديدون من برامج الحماية الاجتماعية

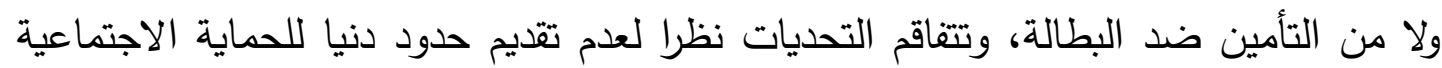
ولذلك ناشدت الإسكوا بعض التدخلات على المستويين الوطني والإقليمي على النحو التالي: 1- دعم المصدرين والمشروعات التجارية المتضررة من تداعيات الفيروس للحد من تسريح العاملين،

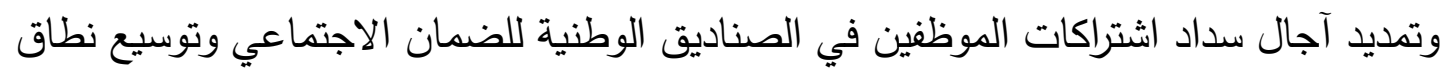
الإعفاءات الضريبية ووقف سداد القروض مؤقتا ودعم تقديم تسهيلات ائتمانيه خلال الأزمة. 2- تطوير التجارة الإكترونية لضمان الاستدامة وتتويع الأسواق، ومن الواضح أن الحكومة المصنية تصرية قد لجأت إلى التخلات في البند (1) من خلال التالى1 - لمواجهة الآثار المحتملة تبنى البنك المركزي عدداً من الإجراءات التحفيزية شملت خفضا

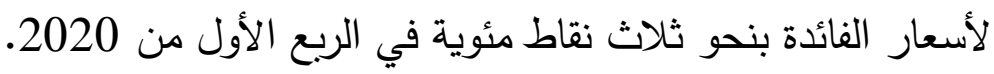
- تأجيل الاستحقاقات الأتمانية للشركات لدده 6 شهور. - اتاحه الحدود الائمانية اللازمة لتمويل راس المال العامل وبالأخص صرف رواتب العاملين

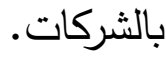

-أعلنت عن حزمه تحفيزيه بقيمه 100 مليار جنيه (50 مليار جنيه للسياحة)، 50 مليار للتمويل العقاري فضلا عن مبادرة البنك المركزي بقيمه 20-30 مليار لبورصة الأوراق المالية لتتشيطها عن طريق شراء للأسهم وعلى الرغم من هذه المبادرات المحمودة إلا أنه تعن لنا عدة ملاحظات: 
* على الرغم من تداعيات كورونا إلا أنه أحد العوامل المخففة من تداعيات انتشار الفيروس هو قوه الاستهلاك العائلي (حيث من المعروف مساهمة بنسبه 85\% في إلاعمالي الناتج المحلى لإنى

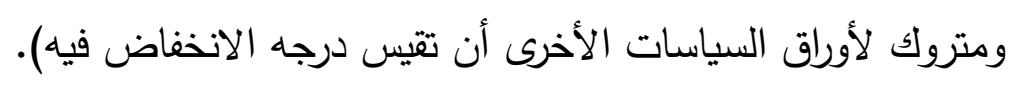

* تساهم جهود دعم العمالة غير المنتظمة في خفض التدهور في المستويات المعيشية للعمالة غير المنتظمة وللقطاع غير الرسمي ولكنها غير كافيه (500 جنيه دعم شهريا لمده ثلاثة شهور )

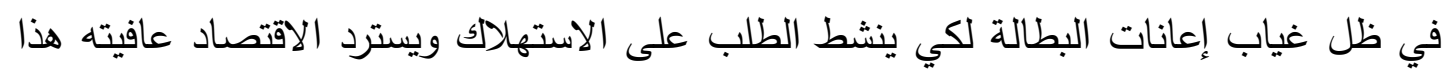

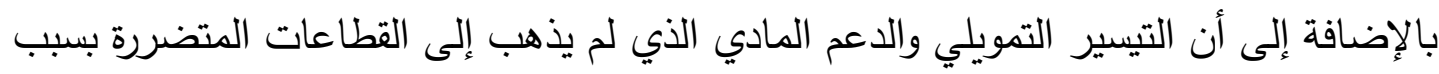

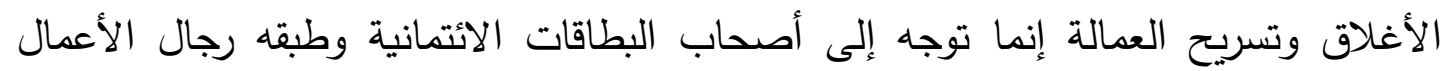
أصحاب الدخول المرتفعة والمتوسطة في الأساس.

* إن قيام الحكومة بتخفيض سعر الفائدة تارة ثم بإصدار شهادات البنك الأهلي بأسعار فائدة

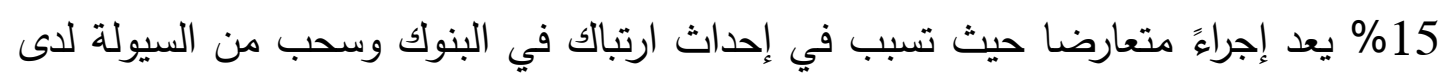

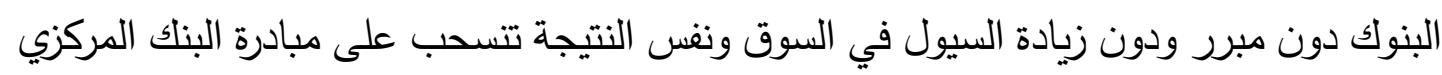

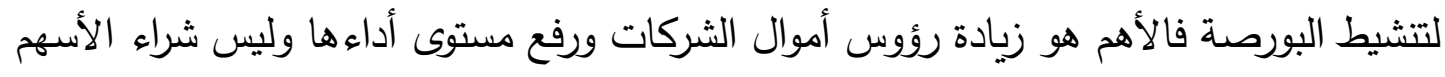

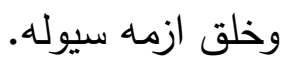

* إن انخفاض موارد العملة الصعبة مع انخفاض تدفقات التحويلات والصادرات والسياحة وإيرادات

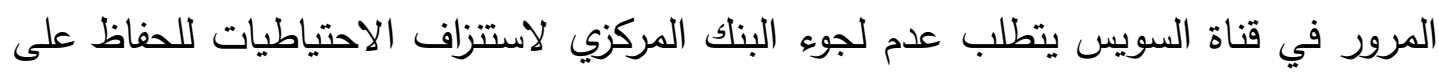

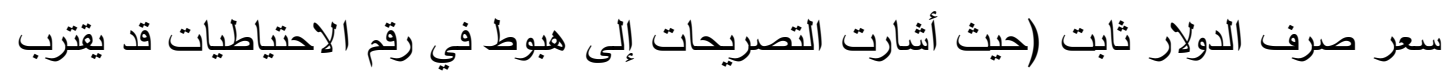
من 15 مليار دولار)

"أشير مؤخراً بوجود توقعات بانخفاض حجم الاستثمار العالمي بنسبه 40\% والحكومة بصدد

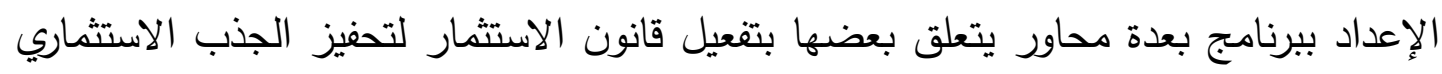

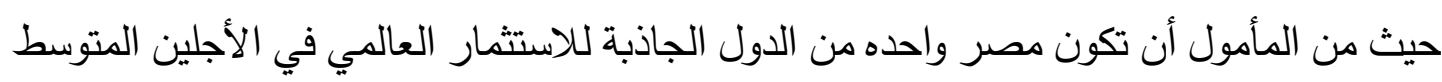

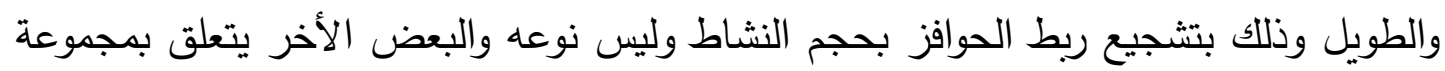

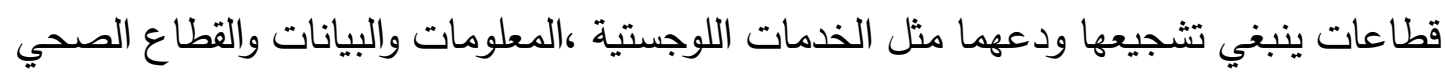

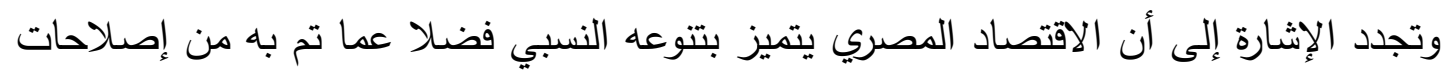

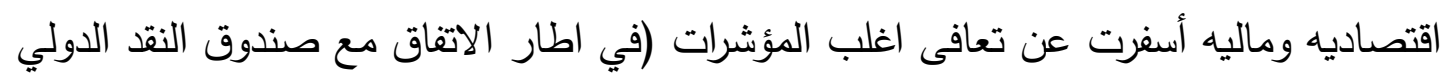

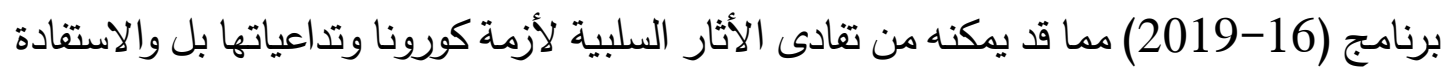

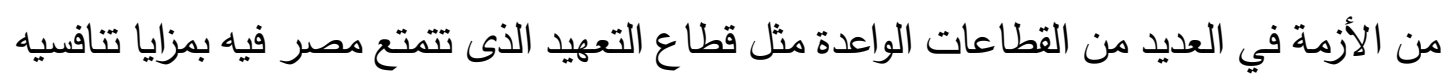


أبرزها رأس المال البشرى وتتافسيه تكاليف التشغيل - الأمر الذى مكنها من احتلال ترتيب متقدم

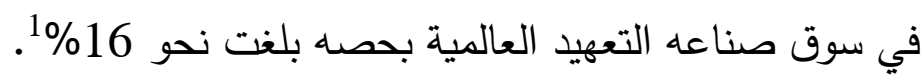

\section{4-2 تدخلات السياسات على المستوى الإقليمي على النحو التالي:}

تعزيز فكر تفعيل منطقه التجارة الحرة العربية الكبرى والتعجيل بفكر استراتيجية تتويع سلاسل الإمداد لتقليص الاعتماد على الصين والاتحاد الأوروبي والولايات المتحدة وغيرها.

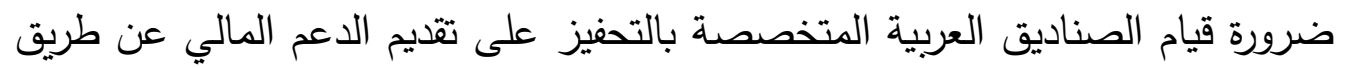
تعميم وتمويل برامج لدعم المصدريين والمستوردين في المنطقة العربية.

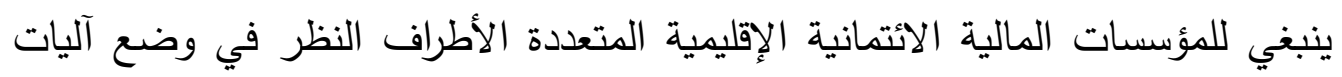

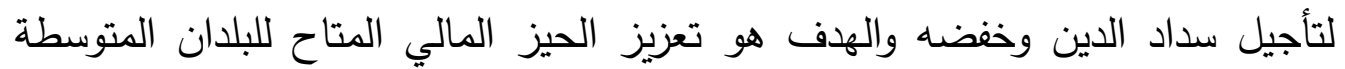
والمنخفضة الدخل في المنطقة. يدعى الدائنون الرسميون إلى الإعلان عن وقف مؤقت لخدمه الديون السيادية في هذه الفترة لتحرير احتياطيات العملات الأجنبية التي تحرم الدول العربية العندية والنامية منها نتيجة استخدامها في خدمة الديون واستيراد معدات الرعاية الصحية واللوازم الطبية. دعوه الصناديق الإقليمية لتوجيه الاستثمارات نحو الصحة والمشروعات الصغيرة

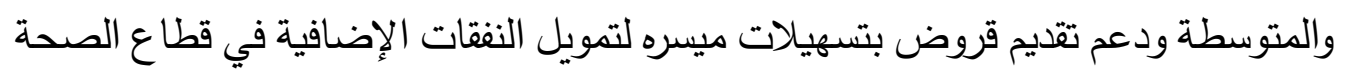
وصرف بدلات إعالة لمن فقدوا وظائفهم مع قيام الصناديق بدعم الدول الأعضاء لبناء مخزون استراتيجي من الأغذية والأدوية. التزام الحكومات العربية بتمكين المهاجرين في البلد المضيفة من تحويل أموالهم إلى أسرهم بطرق منخفضه التكلفة.

3-4 تدخلات بسياسات على المستوى الوطني للتعامل مع تداعيات كورونا على التحويلات:

1- دراسة سبل تقويه قاعده البيانات حول الهجرة الدائمة والمؤقتة وطبيعة البيانات التفصيلية

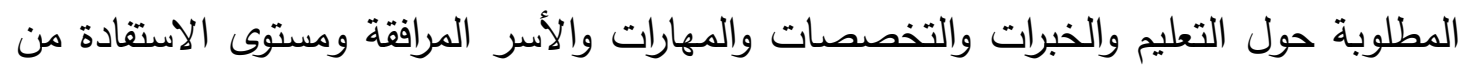

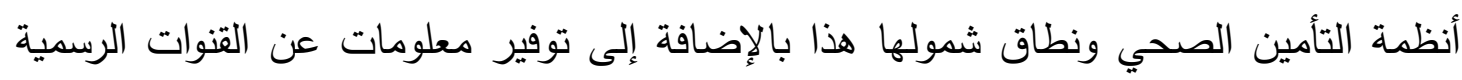
لإرسال التحويلات وطرق استثمارها خلال المكاتب الحكومية.

${ }^{1}$ https:Ilal-ain .com/article/reading-reveals -corona-impact-Egyptian-economy.5/4/2020 
2- أن مستوى التتاغم والتنسيق بين السياسات والقرارات والتنظيمات والمؤسسات المعنية بالهجرة تتطلب التحديد الواضح للأهداف والأولويات وتقويه القدرات المؤسسية وتقيم احتياجات سوق العمل. ويمكن الاستفادة من الآليات المؤسسية التي وضعتها بعض الدول من خلال إنشاء سكرتارية وطنية

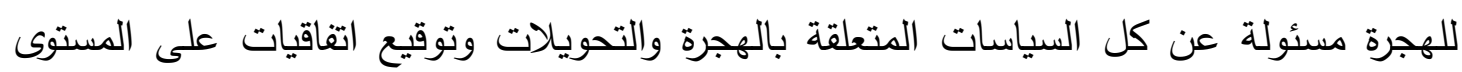
الوطني والدولي مع المؤسسات المحلية الضريبية، البنوك، مكاتب البريد، السجل المدني ومع المؤسسات الخاصة والعامة بالخارج لحماية حقوق المهاجرين وتيسير استرداد مكافآت نهاية المدة لمن تم الاستغناء عنهم وتيسير نقل التحويلات والاعتراف المتبادل بالأمن الاجتماعي.

3- يمكن الاستفادة من تجارب الدول الأخرى في تحسين البنية التحتية لمدفوعات التجزئة للتشجيع الآمن والكفوء للتحويلات من البنك المركزي بإنشاء شبكه فروع من البنوك أو المكاتب في المحافظات والقرى المصرية لتوسيع أنشطتها للتعامل مع محدودي ومنخفضي الدخول وكذلك الاستفادة من تجربه كينيا في نقل الأموال في خلال تطبيقات الهاتف المحمول.

4- يتعين على الحكومة دراسة التحديات والصعوبات في محافظات معينة تعاني من ضعف البنية التحتية ونقص تسهيلات الأعمال الأساسية التي تعوق الاستثمار في المحافظات، مع ضرورة توافر برامج محدده للمحافظات من أجل الأعمال والاستثمار لدى اسر المهاجرين.

5- جذب مدخرات المصرين العاملين بالخارج في إطار الهجرة المؤقتة على النحو التالي:

أ) في ظل التقديرات المتباينة بين المصادر المختلفة فأنه وفقاً للجهاز المركزي للتعبئة العامة والإحصاء 2019 تصل أعدادهم إلى 10.2 مليون فرد في عام 2019، وأن مدخراتهم تقدر ب 150 مليار دولار إلا أن ما يحول فعلياً لا يتجاوز 27 مليار دولار سنويا، وفى ظل افتراض عودة جزء من العمالة المصرية من أسواق مجلس التعاون الخليجي والمقدر عددهم بنحو 5. 4 مليون مصري (في السعودية والأمارات والكويت وقطر) تصبح مهمه الحكومة توفير الآليات المناسبة للاستفادة من هذه المدخرات لهذه الأعداد الكبيرة من المهاجرين سواء هجره دائمه ومؤقته (وحتى أعداد المهاجرين في الولايات المتحدة أستراليا كندا تصل أعدادهم إلى حوالى 2 مليون مهاجر) وحتى مع توقع أن العائدين سيكون اغلبهم من دول الخليج وليس إيطاليا والولايات المتحدة واليونان) فالتوقعات قد تتجاوز أعداد المهاجرين في دول الخليج إبان أزمة الخليج 90-1991 والتي قدرت الأعداد وقتها بحوالي مليون شخص، ولذا فأغلب الظن ألا تقل أعداد المهاجرين العائدين عن 2 مليون مهاجر، ومن المعروف أنه تم حل مشكلة أزمة الخليج الأولى من خلال آلية القطاع غير الرسمي وليس معروفاً كيفية التعامل مع الأزمة المستجدة. 
ب) ويمكن أن نقترح قيام الحكومة بتأسيس صناديق للاستثمار تابعه للحكومة المصرية تقوم إدارتها

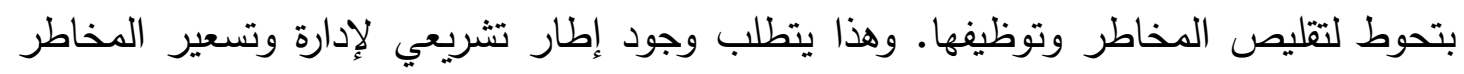
والضمانات.

ج) يقترح أن يقوم الصندوق السيادي لمصر بتأسيس آلية تشارك فيها وزارة التخطيط والدولة لإنثاء شركه ذات غرض خاص SPV وتستخدم الصكوك (على نظام الشريعة الإسلامية) ويساهم فيها

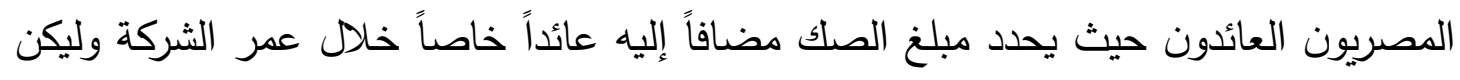
عشر سنوات ثم تتنقل بعد ذلك إلى ملكية الصندوق السيادي أو إنثاء شركات مساهمة. وتقوم

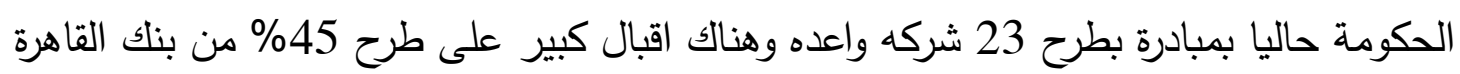
والبنك العربي الأفريقي.

تستهدف هذه الآليات توجيه التحويلات بشكل منتظم للاستخدامات الأكثر إنتاجاً وتقدم فرصاً واعدة

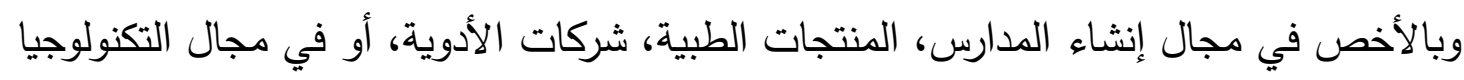
Big Data

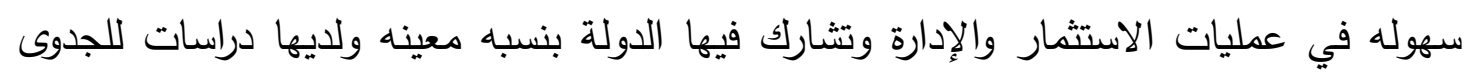

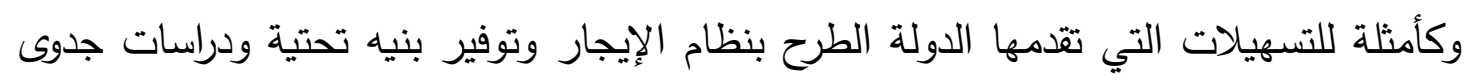

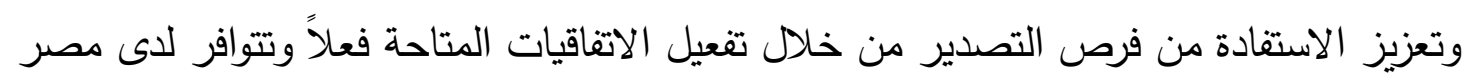

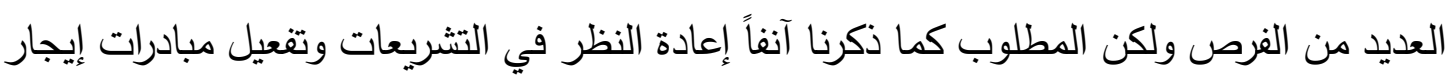
الأراضي. 


\section{المراجع}

\section{أولاً: مراجع باللغة العربية}

الإسكوا، آثار جائحة كوفيد -19 على الاقتصادات العربية: (التجارة والاستثمار الأجنبي

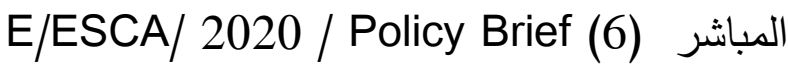

الأنكتاد، الأسعار السلعية الثهرية والسنوية متاحة على الرابط التالي: https://unctadstat.unctad.org/wds/ReportFolders/reportFolders.aspx (10/5/2020).

إيرول بييوك -اتساع الفجوات: اتجاهات تأثير وباء كورونا على الهجرة العالمية - مركز

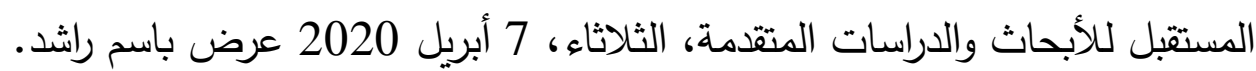
• البناك الدولي، بيان صحفي 2020/4/22.

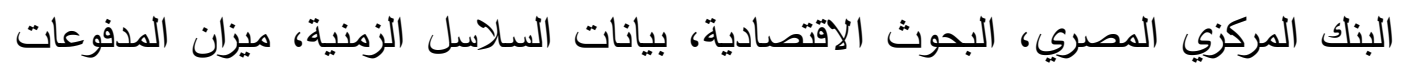
المصري، الاستثمار الأجنبي المباشر، متاحة على الرابط: https://www.cbe.org.eg/_layouts/15/WopiFrame.aspx?sourcedoc=\{F32D 82E4-41F4-44AF-8DB7-3E0B24C76D99\}\&file=BOP(11/5/2020). Annual.xlsx\&action=default التقارير السنوية لمنظمة الأوبك المتاحة على الرابط التالي: (10/5/2020). https://www.opec.org/opec_web/en/publications/338.htm •الجهاز المركزي للتعبئة العامة والإحصاء، النشرة السنوية لتصاريح العمل الصادرة للمصريين

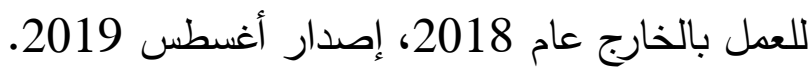
• صندوق النقد العربي، تقرير آفاق الاقتصاد العربي " الإصدار الحادي عشر "اعل، أبريل 2020.

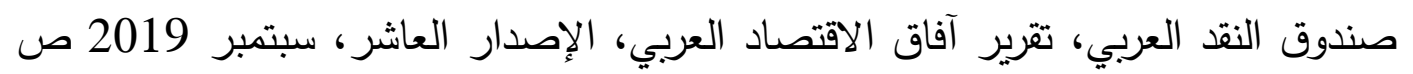

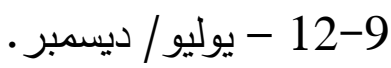

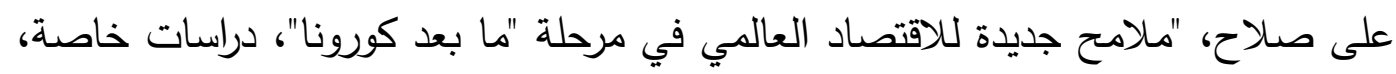

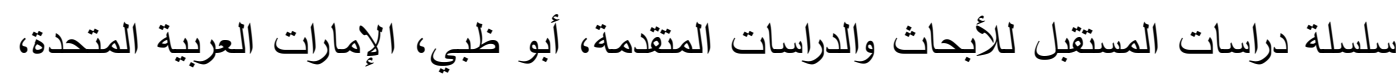
العدد 04-13 أبريل 2020.

فادية عبد السلام، التحويلات ودورها في النمو الاقتصادي (الفصل الثالث) معهد التخطيط القومي (تحرير ) منافع وأعباء التمويل الخارجي في مصر ، سلسلة قضايا التخطيط والتتمية رقم 206، 


$$
\begin{aligned}
& \text { • النشرة السنوية لتصاريح العمل الصادرة للمصريين للعمل بالخارج عام 2018، الجهاز المركزي } \\
& \text { للتعبئة العامة والإحصاء، إصدار أغسطس، } 2019 .
\end{aligned}
$$

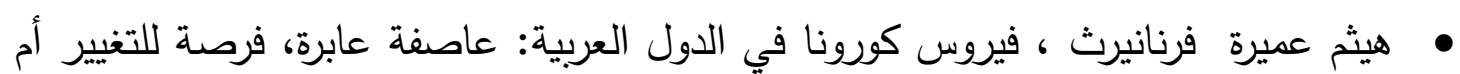

$$
\begin{aligned}
& \text { كارثة إقليمية؟ } \\
& \text { • الوليد أحمد طلحة، التداعيات الاقتصادية لفيروس كورونا المستجد على الدول العربية، صندوق } \\
& \text { النقد العربي، أبريل } 2020 .
\end{aligned}
$$

\section{ثانياً: مراجع باللغة الأجنبية}

- Errol yay-boke, Five ways Coved 019 TsChangeing Global Migration, Centre for Strategic and International Studies.

- https:ll blogs.world ban K.org larl voices lremittances-timesCoronavirus- keep- them- Flowing.

- https:Ilal-ain.com/article/reading-reveals-corona-impact-egyptianeconomy.5/4/2020

- IMF (2020) The Regional Economic outlook: Middle East and Central ASIA, update.

- Real Instituto elcano, ARI 39/2020 (version en' arabe), 7 de abril de 2020.

- World Bank Group, COVID-19 Crisis through a Migration lens, Migration and Development Brief 32, April 2020.

- World Bank Group, Leveraging Economic Migeration for Pevelopment, A Briefing for The world Bank Boordm Sept . 2019.

- world Economic Forum , Emerging Priorities and Principles for managing The Global Economic impact of COVID-19,Chief Economists oat hook , April 2020. 